OPEN ACCESS

Edited by:

Yong-Sung Kim,

Ajou University, South Korea

Reviewed by:

Sang Taek Jung,

Korea University, South Korea

Serge Muyldermans,

Vrije University Brussel, Belgium

${ }^{*}$ Correspondence:

Ario de Marco

ario.demarco@ung.si

He Huang

huang@tju.edu.cn

tORCID:

Ario de Marco

orcid.org/0000-0001-7729-819X

He Huang

orcid.org/0000-0003-3008-4869

ثThese authors have contributed equally to this work

Specialty section:

This article was submitted to Vaccines and Molecular Therapeutics,

a section of the journal

Frontiers in Immunology

Received: 17 December 2021 Accepted: 30 December 2021

Published: 18 January 2022

Citation:

Wang J, Kang G, Yuan $H$, Cao $X$, Huang $H$ and de Marco $A$ (2022) Research Progress and

Applications of Multivalent,

Multispecific and Modified Nanobodies for Disease Treatment.

Front. Immunol. 12:838082. doi: 10.3389/fimmu.2021.838082
Research Progress and Applications of Multivalent, Multispecific and Modified Nanobodies for Disease Treatment

\author{
Jiewen Wang ${ }^{1,2,3 \neq}$, Guangbo Kang ${ }^{1,2,3 \neq}$, Haibin Yuan ${ }^{1,2,3}$, Xiaocang Cao ${ }^{4}$, He Huang ${ }^{1,2,3 * t}$ \\ and Ario de Marco ${ }^{5 * t}$ \\ ${ }^{1}$ Department of Biochemical Engineering, School of Chemical Engineering and Technology, Tianjin University, Tianjin, China, \\ 2 Frontiers Science Center for Synthetic Biology and Key Laboratory of Systems Bioengineering (Ministry of Education), \\ Tianjin University, Tianjin, China, ${ }^{3}$ Institute of Shaoxing, Tianjin University, Zhejiang, China, ${ }^{4}$ Department of Gastroenterology \\ and Hepatology, Tianjin Medical University General Hospital, Tianjin Medical University, Tianjin, China, ${ }^{5}$ Laboratory for \\ Environmental and Life Sciences, University of Nova Gorica, Nova Gorica, Slovenia
}

Recombinant antibodies such as nanobodies are progressively demonstrating to be a valid alternative to conventional monoclonal antibodies also for clinical applications. Furthermore, they do not solely represent a substitute for monoclonal antibodies but their unique features allow expanding the applications of biotherapeutics and changes the pattern of disease treatment. Nanobodies possess the double advantage of being small and simple to engineer. This combination has promoted extremely diversified approaches to design nanobody-based constructs suitable for particular applications. Both the format geometry possibilities and the functionalization strategies have been widely explored to provide macromolecules with better efficacy with respect to single nanobodies or their combination. Nanobody multimers and nanobody-derived reagents were developed to image and contrast several cancer diseases and have shown their effectiveness in animal models. Their capacity to block more independent signaling pathways simultaneously is considered a critical advantage to avoid tumor resistance, whereas the mass of these multimeric compounds still remains significantly smaller than that of an IgG, enabling deeper penetration in solid tumors. When applied to CAR-T cell therapy, nanobodies can effectively improve the specificity by targeting multiple epitopes and consequently reduce the side effects. This represents a great potential in treating malignant lymphomas, acute myeloid leukemia, acute lymphoblastic leukemia, multiple myeloma and solid tumors. Apart from cancer treatment, multispecific drugs and imaging reagents built with nanobody blocks have demonstrated their value also for detecting and tackling neurodegenerative, autoimmune, metabolic, and infectious diseases and as antidotes for toxins. In particular, multi-paratopic nanobody-based constructs have been developed recently as drugs for passive immunization against SARS-CoV-2 with the goal of impairing variant survival due to resistance to antibodies targeting single epitopes. Given the 
enormous research activity in the field, it can be expected that more and more multimeric nanobody molecules will undergo late clinical trials in the next future.

\section{Systematic Review Registration}

Keywords: nanobody multimers, immunomodulation, intrabodies, imaging, nanobody functionalization

\section{INTRODUCTION}

Since the late 1990s, antibodies are largely used in the diagnosis and therapy of neoplastic diseases, including arcitumomab (antiCEA), capromab (anti-PSMA), and trastuzumab (anti-Her2). At the present, engineered monoclonal IgG antibodies represent the majority of the drugs under development for clinical applications $(1,2)$. The reasons for their success with respect to small chemical drugs have been thoroughly reviewed (3), as well as are known the negative characteristics of conventional antibodies. They are large molecules with poor penetration capacity in solid tumors, their engineering and site-specific functionalization is difficult to accomplish and leads to the production of heterogeneous populations with variable distribution and efficiency features (4), and they require expensive production and formulation procedures. Recombinant antibody fragments represent a potential solution to most of such drawbacks and, at the same time, preserve the specificity and the sensitivity of full-length antibodies. Historically, Fabs have been the first class of antibody fragments to be successfully exploited (5-8). The possibility of preparing large libraries of unique clones and to pan them against specific antigens allowed then the isolation of antibody fragments in $\mathrm{scFv}$ and $\mathrm{VHH}$ formats. These miniaturized versions of IgG cannot provide Fc-dependent cellular cytotoxicity and possess no FcRn-dependent prolonged blood circulation but their dimension increases their capacity to penetrate solid tissues and simplifies their humanization and functionalization. Furthermore, they are suitable for the inexpensive production in yeast or bacteria and the design of multivalent or multispecific structures that should improve specificity and apparent binding affinity $(9,10)$. The possibility to create modular constructs by routine molecular biology techniques is particularly interesting when considering that a single binder should be easily converted into reagents with different characteristics according to the final application. For instance, the clearance of a circulating molecule is strictly dependent on its mass. Consequently, an antibody fragment can be fused to a large partner to increase its persistence in the body for a therapeutic application but kept as small as possible to enable rapid in vivo imaging (11). Molecular modifications to extend the serum half-life include conjugation to branched or linear polyethylene glycol (PEG) or fusion with albumin-binding domains, as in the case of ALX-0761 (Table 1). Nanobodies, being at the same time the smallest antibody fragments able to preserve the selectivity and sensitivity of the corresponding fulllength IgG, maximize the design flexibility for creating immunoreagents customized for specific applications. It is also commonly reported that nanobodies are highly stable. This statement is misleading since lab experience shows that single clones possess very diverging levels of stability and aggregation propensity. However, since library panning usually results in the isolation of a large number of individual clones, in most of the cases it is possible to select at least some candidates with optimal biophysical features for the final applications. As a consequence, "published nanobodies" are usually really stable, despite not being representative of the characteristics of the overall nanobody population.

The variety of the applications proposed so far and reported in this work is the confirmation of the nanobody value as reagents for innovative treatments starting from the design of alternative molecular formats. Nanobodies can be grouped together by fusing them to $\mathrm{Fc}$ domain or using linkers to construct multimers. Compared with conventional IgG bispecific antibodies, the structure of bispecific nanobodies (BsNb) is simpler to produce and such constructs show excellent solubility and stability. Due to the relevance of the topic, several reviews dealing with general aspects of engineered antibody fragments were published in the last years (12-15). This review will illustrate the research trends in the field of engineered nanobodies designed for disease treatment because this aspect has not yet dealt with systematically. We analyzed recent studies which dealt with the use of BsNbs and other multimeric $\mathrm{Nb}$ formats in cancer, immune disease and anti-infective therapy to explore the peculiar characteristics of such macromolecules.

\section{NANOBODY APPLICATIONS IN CANCER RESEARCH}

Significant progresses with nanobody immunoreagents have been achieved in the fields of $\alpha$-particle radiation and photodynamic therapy as well as in in vivo imaging (16). Despite no nanobody has been yet approved for cancer treatment (Table 1), nanobody-based multivalent, multispecific and modified constructs have been tested in a multiplicity of cancer applications with therapeutic potential $(17,18)$ (Table 2) and their recombinant nature enables the production of constructs with a wide range of biodistribution and clearance patterns that optimally fit to different applications (43).

\section{Imaging}

Nanobodies are extremely promising imaging reagents in different clinical applications such as fluorescence-guided surgery (44), positron emission tomography (PET) and inglephoton emission computed tomography (SPECT) $(45,46)$. 
TABLE 1 | Multivalent/bispecific nanobodies that entered clinical trials.

\begin{tabular}{|c|c|c|c|c|c|}
\hline Nanobody & Disease & Target & Structure features & Phase of clinical & Clinical trial \\
\hline$A L X-0061$ & $\mathrm{RA}$ & IL6R & Bivalent albumin-conjugated & Phase II & NCT0251862 \\
\hline$A L X-0061$ & SIE & & & Phase II & NCT02437890 \\
\hline ATN-103 & RA & TNF & Trivalent albumin-conjugated & Phase ॥ & NCT01063803 \\
\hline$A L X-0761$ & Psoriasis & IL17A/L17F & $\begin{array}{l}\text { Trivalent bispecific } \\
\text { Albumin-conjugated }\end{array}$ & Phase II & NCT03384745 \\
\hline M1095 & Psoriasis & IL17A/IL17F & Bivalent bispecific & Phase II & NCT03384745 \\
\hline Caplacizumab & TTP & WF & Bivalent monospecific & Approved & NCT02878603 \\
\hline ALX-0171 & RSV & F-protein RSV & Trivalent monospecific & Phase ॥ & NCT02979431 \\
\hline ALX-0651 & Healthy volunteers & CXCR4 & Bivalent bispecific & Phase I & NCT01374503 \\
\hline Bl836880 & Solid tumors & Angiopoietin/VEGF & Bivalent bispecific & Phase I & NCT02674152 \\
\hline KN046 & Squamous Non small-cell Lung Cancer & PD-L1/TLA4 & Tetravalent bispecific & Phase III & NCT04474119 \\
\hline KN046 & Advanced HCC & PD-L1/CTLA4 & Tetravalent bispecific & Phase I & NCT04601610 \\
\hline KN035 & Hepatocellular Carcinoma & PD-L1 & Bivalent monospecific & Phase I & NCT03101488 \\
\hline BCMA nanobody CAR-T cells & Relapsed/Refractory Myeloma & $\mathrm{CD} 8 / 4-1 \mathrm{BB}$ & CAR-T & Phase I & NCT03664661 \\
\hline CD7 CAR-T cells infusion & T-lymphoblastic Lymphoma & CD7 & CAR-T & Phase I & NCT04004637 \\
\hline CD22 CAR-T cells & B-Cell Lymphoma & CD22 & CAR-T & Phase I & NCT03999697 \\
\hline$\gamma \delta \mathrm{T}$ Cell infusion agent & B-cell Leukemia & & CAR-T & Early Phase 1 & NCT04439721 \\
\hline CD19/CD20 CAR-T cells & B-Cell Lymphoma & CD19/CD20 & CAR-T & Phase I & NCT03881761 \\
\hline aPD1-MSLN-CAR T cells & $\begin{array}{l}\text { Non-small-cell Lung Cancer } \\
\text { Mesothelioma }\end{array}$ & PD-1 & CAR-T & Early Phase I & NCT04489862 \\
\hline aPD1-MSLN-CAR T cells & Colorectal Cancer & PD-1 & CAR-T & Phase I & NCT05089266 \\
\hline M6495 & Symptomatic Knee Osteoarthritis & ADAMTS-5 & Bivalent bispecific & Phase II & NCT03583346 \\
\hline
\end{tabular}

https://clinicaltrials.gov/.

TABLE 2 | Multivalent/bispecific nanobodies proposed for cancer therapy.

\begin{tabular}{|c|c|c|c|c|c|}
\hline Nanobody & Disease & Target & Structure features & Year & Reference \\
\hline MaAbNA & Breast cancer & HER2/EGFR & Bivalent bispecific & 2015 & (19) \\
\hline ENb-TRAIL & Lioblastoma & EGFR/DR & Bivalent bispecific & 2017 & (20) \\
\hline dhuVHH6-PE38 & Acute lymphoblastic leukemia & CD7 & Bivalent monospecific & 2017 & (21) \\
\hline nanoCAR & B cell leukemia & HER2/CD20 & Bivalent bispecific & 2018 & (22) \\
\hline 7D12-5GS-6H4 & Cancer immunotherapeutic & EGFR/ $\gamma \gamma 9 V \delta 2-T$ & Bivalent bispecific & 2018 & (23) \\
\hline$\alpha$-EGFR-EGFR TM & $\mathrm{EGFR}^{+}$tumor & EGFR & Bivalent monospecific & 2018 & (24) \\
\hline RR2-H-RR4 & Breast cancer & Her2 epitopes & Bivalent bispecific & 2018 & (25) \\
\hline NB-hcAb & Multiple myeloma & CD38 & Bivalent monospecific & 2018 & (26) \\
\hline Muc1-Bi-2 & Ovarian cancer & Muc1/CD16a & Bivalent bispecific & 2018 & (27) \\
\hline $\mathrm{BiNb}$ & Angiogenesis & VEGF & Bivalent monospecific & 2019 & (28) \\
\hline bsVHH & Chronic lymphocytic leukemia & CD1d/N $\gamma 9 \vee \delta 2-T$ & Bivalent bispecific & 2019 & (29) \\
\hline BiSS & Colorectal cancer & CEA/CD16a & Bivalent bispecific & 2020 & (30) \\
\hline Biss CAR & Acute myeloid leukemia & CD13/TIM3 & Tetravalent bispecific & 2020 & (31) \\
\hline CD47/CD20 BsAb & Acute myeloid leukemia & CD47/CD20 & Tetravalent bispecific & 2020 & (32) \\
\hline $\mathrm{Bi} 2$ & $\mathrm{EGFR}^{+}$tumor & EGFR/FP & Bivalent bispecific & 2020 & (33) \\
\hline bi-Nb & Angiogenesis & PLGF & Bivalent monospecific & 2020 & (34) \\
\hline NbEGFR-HSA-CD16 & EGFR $^{+}$tumor & EGFR/HAS/CD16 & Trivalent tri-specific & 2021 & (35) \\
\hline CAM1615HER2 & Breast cancer & CD16/HER2/IL15 & $\begin{array}{l}\text { Bivalent bispecific } \\
\text { Antibody-cytokine fusion protein }\end{array}$ & 2021 & (36) \\
\hline S7 ADC & EGFR+ tumor & EGFR & Tetravalent monospecific & 2021 & (37) \\
\hline multivalent PD-L1/TIGIT BsAb & Colon cancer & PD-L1/TIGIT & Multivalent bispecific & 2021 & (38) \\
\hline C21-7D12/7D12-C21 & Colorectal cancer & EGFR/CD16 & Bivalent bispecific & 2021 & (39) \\
\hline 48-(G4S)1-32/32-(G4S)1-48 & Leukemia & EGFR/CD16 & Bivalent bispecific & 2021 & $(40)$ \\
\hline Bispecific Nb CAR & Lymphoma & CD19/CD20 & Bivalent bispecific & 2021 & (41) \\
\hline 11A4-ABD-AF & Breast cancer & HER2/HSA & Bivalent bispecific & 2021 & (42) \\
\hline
\end{tabular}

In cancer in vivo imaging, nanobodies have been successfully used to specifically deliver radionucleotides to tumor cells, to biomarkers of the tumor microenvironment and to monitor immune infiltration in animal models and clinical trials (16). The major drawback of the conventional PET protocol that exploits the preferential accumulation of glucose in tumors to deliver radionucleotide-labeled glucose analogues to the cancerous site is that organs such brain or heart, which have high glucose consumption, are difficult to imagine because of the elevated background signal. Antibodies complexed to radionuclides and specific for tumor surface biomarkers represent a rational alternative for selective targeting but the large dimension of IgGs impairs the fast clearance of the unbound fraction. IgGs persist for a couple of days in the 
vessels determining a diffuse background that prevents high resolution imaging in the first 24-48 hour after administration. However, waiting for days between radionucleotide injection and imaging is impracticable in the clinical organization. Therefore, the optimal solution appears using antibody fragments such nanobodies that are cleared in 15 min by kidney filtration but still provide excellent target accumulation, effective tumor penetration and improved tumor-to-background signal with respect to labeled glucose $(47,48)$. This approach brings a further advantage: since the imaging can be performed within one hour after the reagent injection, it is possible to use the short half-life positron-emitting nuclides (18F, 68Ga or $89 \mathrm{Zr}$ ) for PET and the $\gamma$-emitting nuclide $(99 \mathrm{mTc})$ for SPECT to diminish unnecessary patient irradiation (17). Given the simple engineering of nanobodies, they can be simply expressed as bivalent molecules that still preserve low mass but have increased avidity. For instance, with respect to the monovalent $\alpha$-EGFR construct, its corresponding bivalent format resulted in higher accumulation at the tumor site and improved PET imaging (24).

\section{B-Cell Lymphomas/Leukemias}

B cell lymphoma and leukemia are the most common subtypes of malignant lymphomas and represent $80-85 \%$ of non-Hodgkin lymphomas (NHLs). About $20 \%-40 \%$ of B-cell lymphoma/ leukemia patients die due to relapse after Rimximab treatment (49). CAR-T cell therapy has shown potential efficacy in the treatment of B cell leukemias and lymphomas and the contemporary targeting of multiple antigen epitopes has been envisaged to overcome the emergence of single antigen-resistant leukemic cells and avoid immune escape (50, 51) (Figure 1). Nanobodies targeting CD19, CD20, CD30 and CD22 (52) have been successfully used for CAR applications.

De Munter et al. (22) reported the generation of a bispecific CAR comprising two nanobodies specific for CD20 and HER2, respectively. $T$ cells expressing the bispecific nanoCAR were able to kill tumor cells over-expressing CD20, HER2, or both antigens. Since the individualized manufacturing process of (nano)CARs is costly, the attention moved to donor-derived $\gamma \delta \mathrm{T}$ cells to use as a CAR backbone because $\gamma \delta \mathrm{T}$ cells lack allogenicity and are known to mediate natural anti-tumor responses (54). De Bruin et al. constructed a bispecific nanobody-based structure that targets $\mathrm{V} \gamma 9 \mathrm{~V} \delta 2-\mathrm{T}$ cells and EGFR for cancer immunotherapeutic therapy (23). Biotech companies such as PersonGen BioTherapeutics developed nanobody-based CAR- $\gamma \delta \mathrm{T}$ cells to treat B-cell leukemia. A clinical trial is currently under way to test the safety and effectiveness of donor $\gamma \delta \mathrm{T}$ cell infusion to prevent relapsed/ refractory leukemia rescue relapse after allogeneic hematopoietic stem cell transplantation. Moreover, $\mathrm{V} \gamma 9 \mathrm{~V} \delta 2-\mathrm{T}$ cells have become a novel potential immunotherapeutic for Chronic Lymphocytic Leukemia (CLL) due to their capacity to be triggered by phosphoantigens which are overproduced by CLL. A nanobody-based CD1d-specific $\mathrm{V} \gamma 9 \mathrm{~V} \delta 2-\mathrm{T}$ cell engager was generated to induce robust activation and degranulation of Vg9Vd2-T cells and consequent lysis of autologous leukemic cells (29).

\section{Acute Myeloid Leukemia (AML)}

Acute myeloid leukemia (AML) includes all acute nonlymphocytic leukemia. It is related to the insurgency of pluripotent stem cells or slightly differentiated progenitor cell nuclear type mutations. A Sequentially Tumor-Selected Antibody and Antigen Retrieval (STAR) system (31) was developed for screening multiple nanobodies that specifically target AML cells. Nanobodies were used to enhance the binding efficacy of CAR-T cells to AML cells. To this aim, the anti-CD13 nanobody $\mathrm{Nb} 157$ was isolated and used to target CD13+ AML cells. Further, bispecific CAR-T cells targeting CD13 and TIM3 were designed to eradicate patient-derived AML and to promote decreased toxicity to human bone marrow stem cells and peripheral myeloid cells in mouse models (Figure 1).

CD47 is overexpressed in gastric, ovarian and colon cancer, as well as in AML (55) and an anti-CD47 nanobody (HuNb1-IgG4)

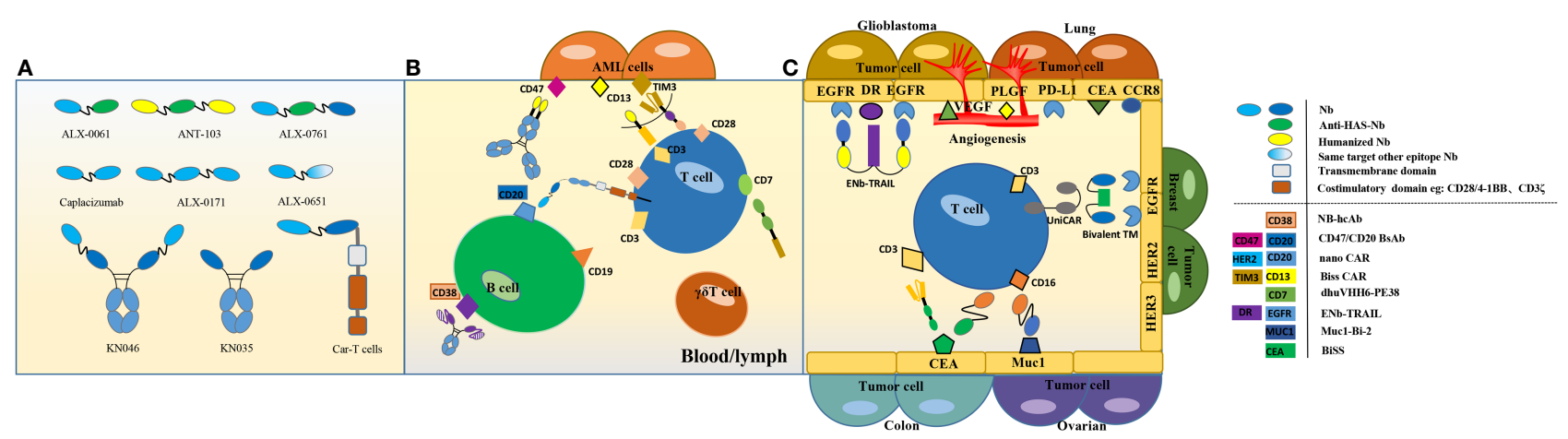

FIGURE 1 Formats and strategies for multivalent/multispecific nanobodies. (A) Formats of multivalent mono/bispecific nanobodies that entered in clinical trials. (B) Multivalent mono/bispecific nanobodies applications for blood/lymph cancer therapy. Several CAR-T cell therapies are based on nanobodies and have shown promising effects, for instance in B cell lymphoma. The most commonly targeted receptors on B- and T-cells are CD19, CD20 and CD3, respectively (52). (C) Multivalent/bispecific nanobody applications for solid cancer therapy target surface biomarkers of epithelial cancer cells. Multi-functional nanobody structures target multiple epitopes or antigen combinations, resulting in synergistic therapeutic effects for tumors that do not respond to single-target antagonists (53). 
with high affinity and specificity (32) effectively empowered macrophage-mediated phagocytosis of tumor cells in vitro. In vivo it showed potent anti-ovarian cancer and anti-lymphoma activity and its efficacy was further increased when it was combined with rituximab to build a bispecific antibody for the simultaneous targeting of CD47 and CD20.

\section{Acute Lymphoblastic Leukemia (ALL)}

Acute lymphoblastic leukemia is a highly invasive type of blood cancer. Blinatumomab, which was approved by FDA in late 2014 for the treatment of Fischer-negative precursor ALL (Figure 2), is a bispecific antibody based on the BiTE technology and employing two scFvs. One targets the CD19 antigen on the surface of tumor cells, whereas the other targets the CD3 receptor on the surface of cytotoxic T lymphocytes (57). Nanobodies were used in alternative configurations to contrast ALL. CD7 is a convenient ALL biomarker of T-cells (59) because it is rapidly endocytosed once complexed by antibodies and therefore can be exploited for biotherapeutic uptake. A set of humanized antiCD7 nanobodies was characterized. With respect to the monovalent version, bivalent formats fused to a truncated derivative of Pseudomonas exotoxin A showed significant higher cytotoxicity $(60,61)$. The fusion dhuVHH6-PE38 was used in vivo in NOD-Prkdc ${ }^{\mathrm{em} 26} \mathrm{IL} 2 \mathrm{rg}^{\mathrm{em} 26} \mathrm{Nju}$ (NGG) mouse model and significantly extended the survival of the animals. The same nanobody was successfully used to create CAR constructs which significantly inhibited disease progression in xenograft mouse models of T-ALL primary tumor cells (21).

\section{Multiple Myeloma}

Multiple myeloma is a neoplastic plasma-cell disorder that arises from an asymptomatic premalignant proliferation of monoclonal plasma cells derived from post-germinal-center B cells. CD38 is considered as a biomarker overexpressed in multiple myeloma and the anti-CD38 monoclonal antibody daratumumab demonstrated its high therapeutic efficacy (62).

Schütze et al. isolated a set of nanobodies that recognized three different non-overlapping epitopes of CD38 extracellular domain and then prepared biparatopic constructs by fusing two nanobodies, specific for alternative epitopes, to human IgG1 Fcdomain (26). These constructs outscored both the monoclonal daratumumab and bivalent constructs sharing the same geometry by displaying two identical nanobodies when compared for their capacity of mediating complementdependent cytotoxicity toward CD38-expressing myeloma cells.

$B$ cell maturation antigen is expressed extensively in malignant plasma cells, seems to be involved in their proliferation and survival and is regarded as a target for CAR-T therapy, despite the possible side effects $(63,64)$. Nanobody-based CAR-T molecules targeting such receptor are under development in biotech companies but no scientific publication confirms their efficacy.

\section{Angiogenesis}

Tumors require active angiogenesis for securing the energy necessary for their growth and the factors regulating this process become potential drug targets. Vascular endothelial growth factor (VEGF) plays a critical role in the angiogenesis (65) and the high-affinity anti-VEGFR2 nanobody (3VGR19) (28) was tested for its capacity in inhibiting proliferation, tube formation, and migration of human endothelial cells. When built into a bivalent format using the hinge region of llama IgG2c, its half-life in vivo in a C57BL/6 mice model was almost doubled and its inhibitory activity was significantly higher than those obtained using the monovalent nanobody.

Placental growth factor (PlGF) is a structurally related member belonging to the same superfamily of VEGF (66) and

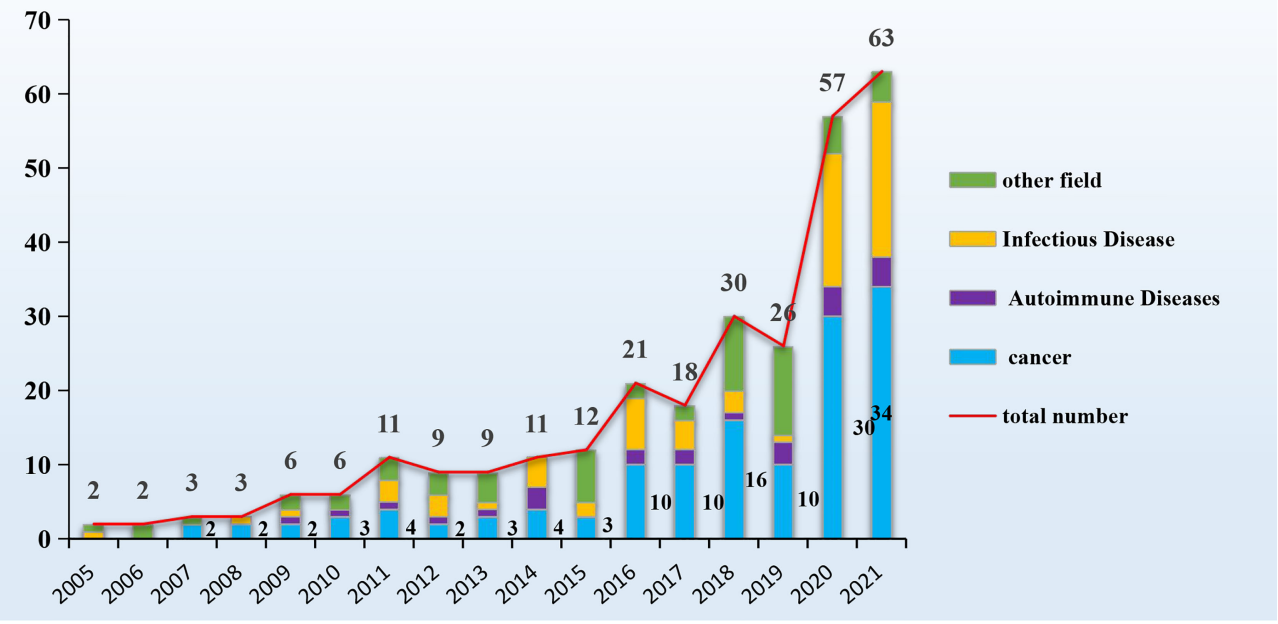

FIGURE 2 | Timeline of conceptual and technical innovations contributing to the development of the multi-function nanobody landscape. The Camelidae "heavychain-only antibodies" were first reported by Hamers-Casterman et al. (7) in 1993 and the first bispecific antibody (Catumaxomab) was approved by EMA only in 2009 (56). In 2014, the first bispecific scFv (Blinatumomab) was approved by FDA (57) and the same agency approved, the first bivalent nanobody drug (Caplacizumab) for treatment of acquired thrombotic thrombocytopenic purpura (TTP) in 2019 (58). 
might be involved in pathogenic angiogenesis, probably by recruiting myeloid progenitors (67). Nikooharf et al. (34) developed a bivalent anti-PLGF nanobody to test as suppressor of the angiogenesis progression and observed that it could inhibit cell proliferation, capillary-like structure formation and motility.

\section{Glioblastoma}

Glioblastoma is the most common primary brain tumor in adults and usually leads to rapid death. A therapeutic option considers targeting the death receptor (DR) to activate tumor cell death pathway but the variable response degree in tumor cells to DR agonist-mediated apoptosis represents a major limitation of this approach.

A bispecific construct (ENb-TRAIL) composed by an antiEGFR nanobody and the DR ligand TRAIL demonstrated therapeutic efficacy in tumor cells that do not respond to either EGFR antagonist or DR agonist monotherapies (Figure 1). ENbTRAIL induced a triple anti-tumor effect by inducing DR5 aggregation in the plasma membrane, by initiating caspasemediated apoptosis of tumor cells and by blocking the EGFR signaling pathway. In vivo assays proved that ENb-TRAIL treatment significantly alleviated tumor burden and increased survival $(20,68)$. A tetravalent anti-DR5 agonistic nanobody construct (TAS266) showed more potency than the ENb-TRAIL compound in pre-clinical studies but did not passed Phase I due to its strong hepatotoxicity (69).

Brain is also the site of metastatic tumors. A bispecific antiVEGF-A/Ang2 nanobody was able to reduce significantly number and volume of metastatic tumors in a mouse model (70).

\section{Lung Cancer}

Lung cancer is the leading cause of cancer death worldwide and, among the different subtypes, non-small cell lung cancer (NSCLC) accounts for about $85 \%$ of the whole cases (71). The trifunctional bispecific antibody Catumaxomab based on Quadroma (Hybrid Hybridoma) technology, which combines the EpCAM rat antibody (IgG2b) and CD3 mouse antibody (IgG2a) into a bispecific molecule (56), was the first multispecific antibody approved by EMA (2009) for the treatment of NSCLC malignant ascites (Figure 2). Other not exclusive biomarkers, such epidermal growth factor receptor (EGFR), are often considered as therapeutic targets in NSCLC because highly overexpressed and often mutated. An anti-EGFR nanobody combined with photosensitizer and catalase succeeded in improving tumor hypoxia and consequently killed A549 primary tumor and inhibited lung metastasis, prolonging mouse survival (72). Also anti-EGFR nanobodies functionalized with a cell-penetration poly-arginine peptide were highly cytotoxic to the same human adenocarcinomic alveolar basal epithelial cells A549 (73).

About 33\% of patients with NSCLC tumors and epidermal growth factor receptor mutations develop brain metastasis (74). Osimertinib is effective against mutated EGFR but drug resistance raises in 1 to 2 years (75). To overcome this limitation, dual-targeting liposomes were generated that display an anti-PD-L1 nanobody and a transferrin receptorbinding peptide. This construct is still able to pass the blood- brain barrier and mediate simvastatin/gefitinib delivery to the NSCLC-EGFR ${ }^{\text {mut }}$ metastatic tumor (76).

Nanobodies were also exploited to assess alternative biomarkers and therapeutic options. A technetium-99 mlabeled anti-CEA nanobody was used to prove that the carcinoembryonic antigen (CEA) was a potentially interesting marker for NSCLC (77), whereas bright nanoprobes based on quantum dots conjugated to anti-HER2 nanobodies provided better immunolabeling of lung cancer cell lines than dyes Alexa Fluor 488 and Alexa Fluor 568 (78). Multivalent anti-CCR8 nanobodies fused to Fc were also effective in NSCLC treatment by eliciting antitumor immunity through tumor-promoting Treg cells depletion and ADCC activation (79). Since angiogenesis is critical in tumor development, VEGFR2 was targeted by an antiVEGFR2 nanobody conjugated with the enzyme urease that can convert endogenous urea into ammonia, a product toxic to tumor cells (80).

\section{Breast Cancer}

Breast cancer is the second most common cancer in women and the one causing more deaths. According to the genetic and biochemical characteristics, breast tumors are grouped into three major classes (Estrogen/Progesterone receptor positive, Her2 positive, Triple Negative - TN), with further stratification describing the subtypes of Triple Negative (81). About $20 \%$ of breast cancers are characterized by amplification of the HER-2/neu gene (82). HER2 is a tyrosine kinase receptor the overexpression of which causes increased tumor cell proliferation, tumor invasiveness, accelerated angiogenesis, and reduced apoptosis (83). Anti-HER2 monoclonal IgG antibodies trastuzumab (Herceptin) and pertuzumab, which target independent epitopes, are widely used alone or in combination in clinical treatment of HER2-positive breast cancers $(84,85)$. Nanobodies that bind to the same epitopes recognized by such IgGs have a potential therapeutic interest (36, $42,86)$, whereas those that do not interfere with their binding because target further epitopes are suited for imaging or can be used as complementary theranostic reagents (87-90).

Since nanobodies specific for Her2 are simple to generate (43) and as recombinant proteins are simple to engineer, anti-Her2 nanobodies have been exploited to develop an enormous variety of reagents, such as bivalent and biparatopic molecules (25), immunotoxins $(91,92)$, activated nanoparticles $(25,93-95)$, biosensor immunocapture surfaces and other nanostructures suitable for receptor detection (96-101) and have been also in silico modeled to increase their biophysical features (102). As a general rule, multivalent formats provide higher apparent affinity for their antigen due to the avidity effect. Furthermore, multispecific formats are often more effective in inhibiting cell proliferation because of their capacity to block contemporarily alternative activation pathways $(19,103)$. The number of nanobodies available for TN breast cancers is extremely lower. TN positive cells have been successfully targeted with anti-EGFR-activated Quantum-Dot theranostic micelles, anti-STAT3 and anti-Protein C Receptor nanobodies and antiTNF $\alpha$ nanobodies used alone or fused to a recognition peptide binding to the $\alpha v \beta 3$ receptor on tumor cell membranes (104108).The common limit of these approaches is that the targeted 
biomarkers are not exclusive of TN cells and therefore their clinical usefulness remains to be demonstrated. There is no report of nanobodies used for the diagnostic or the therapy of Estrogen/Progesterone receptor positive breast tumors.

\section{Ovarian Cancer}

Ovarian cancer is characterized by tumor heterogeneity and by controversial diagnostic methodology (109). Nanobody-activated nanospheres were successfully used for developing a highly sensitive (detection limit of $0.560 \mathrm{pg} \mathrm{mL}^{-1}$ ) photoelectrochemical biosensor able to detect the serum biomarker Human Epididymis Protein 4 (HE4) and clearly distinguish ovarian cancer patients from healthy individuals (110). Mucins are type I membrane O-glycoproteins with single transmembrane domains that are usually highly upregulated during tumorigenesis and could represent a therapeutic target (111). In this perspective, Li et al. (27) designed a bispecific construct (Muc1-Bi) constituted by two nanobodies, one specific for Muc1 and the second for CD16 that could be applied for ovarian cancer treatment. This reagent can recruit NK cells and drive them to Muc1-overexpressing tumor cells and, in a xenograft model, significantly suppressed tumor growth.

\section{Colon Carcinoma}

Despite being expressed in several tumors, CEA is often used as a biomarker of colon carcinoma (112). CdSe/ZnS quantum dots conjugated to an anti CEA nanobody have been used as efficient two-photon excitation probes for imaging colon carcinoma tissue (113), whereas a bispecific construct formed by linking anti-CEA and anti-CD16a nanobodies succeeded in engaging NK cells and inhibiting CEA-overexpressing tumor growth in vivo (30) (Figure 1). A novel bispecific nanobody with dual PDL1/TIGIT demonstrated high inhibitory activity towards both PD-1/PD-L1 and TIGIT/CD155 interactions. Its application synergistically enhanced $\mathrm{T}$ cell activity in vitro compared to that of the two parental nanobodies (38) and such strategy for treating tumors might improve the reliability of therapies aiming at immune checkpoint blockade.

\section{NANOBODY APPLICATIONS FOR AUTOIMMUNE DISEASES}

Antibodies represent a powerful means for the treatment of immune diseases because they can target ligands or receptors involved in the abnormal amplification of molecular signals responsible for the symptoms. Currently, there are antibodies approved for treating autoimmune diseases such as rheumatoid arthritis, inflammatory bowel disease, type 1 diabetes, psoriasis, lupus, and multiple sclerosis (114). Even though this implies the necessity of more frequent treatments, antibody fragments with short half-life period are considered safer because of their reduced retention time and their engineering into dual-target reagents provides the advantage of blocking pairs of inflammatory cytokines at the same time, increasing the treatment efficacy (7) (Table 3).

\section{Inflammatory Bowel Disease}

Inflammatory bowel disease (IBD) is a multifactorial disorder characterized by chronic and relapsing intestinal inflammation. IBD includes ulcerative colitis (UC) and Crohn's disease (CD) that affects the ileum, rectum, and colon. Nowadays, inflammatory bowel disease cannot be completely cured, but anti-TNF- $\alpha$ monoclonal antibodies, such as infliximab and adalimumab, have made a significant breakthrough by enabling the delay of IBD progression (121). Moreover, their rapid mucosal healing ability has improved the response and remission rate of patients with $\mathrm{IBD}$, especially for $\mathrm{CD}$ treatment (122). Tumor necrosis factor (TNF) is a pro-inflammatory cytokine that represents a critical mediator of the autoimmune process, playing a key role in several inflammatory diseases, including rheumatoid arthritis (RA), ulcerative colitis, and CD. An innovative therapeutic approach for treatment of chronic colitis considered the in situ secretion of anti-TNF nanobodies by orally administered L. lactis bacteria engineered to secrete monovalent and bivalent anti-TNF nanobodies that neutralized TNF in vivo (115). TNF is the target of further inhibitory nanobodies. A trispecific anti-TNF construct could effectively inhibit the TNF/TNFR1 signaling pathway and its inhibitory activity was successfully tested ex vivo using colon biopsies of CD patients (117). In another study, three anti-TNF nanobodies with sub-nanomolar affinity for their antigen were selected and the crystal structures of the TNF-nanobody complexes showed that they targeted (partially) overlapping epitopes (119). Nevertheless, bivalent molecules showed increased blocking activity due to the fact that, differently from conventional antibodies, these constructs can bind simultaneously to two independent receptor binding sites of the trimeric TNF.

Recent studies have shown that IL-23 mediates the overproliferation of $\mathrm{T}(\mathrm{H})-17$ cells and the resulting accumulation of IL-17 and IL-22 pro-inflammatory cytokines promotes dermal inflammation and CD pathogenesis (123). Anti-human IL-23 nanobodies with low nanomolar affinity for hIL-23 and targeting

TABLE 3 | Multivalent mono/bispecific nanobodies for autoimmune diseases.

\begin{tabular}{|c|c|c|c|c|c|}
\hline Nanobody & Disease & Target & Structure features & Year & Reference \\
\hline MT1 - MT1 & Inflammatory Bowel disease & TNF- $\alpha$ & Bivalent monospecific & 2010 & $(115)$ \\
\hline ATN-103 & Rheumatoid artheiris & $\mathrm{TNF}-\alpha$ & Bivalent monospecific & 2012 & $(116)$ \\
\hline TROS & Inflammatory Bowel disease & TNFR1 & Bivalent bispecific & 2015 & $(117)$ \\
\hline 37D5-Alb1-124C4 & Chronic inflammation & IL23 & Bivalent monospecific & 2017 & $(118)$ \\
\hline VHH\#3-9GS-VHH\#1 & Inflammatory Bowel disease & TNF- $\alpha$ & Bivalent monospecific & 2017 & (119) \\
\hline M1095 & Psoriasis & $\| \mathrm{L}-17 \mathrm{~A} / \mathrm{F}$ & Bivalent bispecific & 2017 & $(120)$ \\
\hline
\end{tabular}


independent epitopes were assembled together with an antihuman serum albumin nanobody into multivalent constructs. They showed prolonged in vivo half-life and improved hIL-23 neutralization capacity in vitro and in vivo with respect to the single monomeric nanobodies (118).

\section{Psoriasis}

The above described anti-IL23 multivalent nanobodies might be suitable for treating psoriasis as well. Furthermore, current studies suggest that another effective treatment method would be the inhibition of IL-17 (120). M1095 is a trivalent bispecificnanobody that can effectively neutralize the pro-inflammatory cytokines IL-17A and IL-17F as well as bind to human serum albumin. The initial clinical trials to evaluate the safety and effectiveness of the immunoreagent in patients with moderate to severe psoriasis showed that M1095 was well tolerated whereas psoriasis-related inflammatory markers were significantly decreased (120).

\section{Rheumatoid Arthritis}

Rheumatoid Arthritis (RA) is a common chronic autoimmune disease. Tumor necrosis factor- $\alpha$ (TNF- $\alpha$ ), as a pleiotropic cytokine, induces adverse pro-inflammatory and cytotoxic effects in the course of RA. A preliminary work showed that antagonistic anti-TNF nanobodies linked to an anti-serum albumin nanobody were 500 times more effective than monovalent nanobodies in controlling rheumatoid arthritis development in a mouse model (124). The bispecific nanobody format showed also higher antagonistic potency than the commercial IgG antibodies infliximab and adalimumab. On the base of such experience, it was designed the compound ATN-103 (ozoralizumab), a trivalent bispecific albumin-conjugated nanobody that targets TNF- $\alpha$. In Phase II clinical trials it showed to cause no immunogenic response (116). Taisho Pharmaceuticals performed an apparently successful Phase III with this multimeric nanobody and recently submitted an application for approval to manufacture and market the immunodrug (Table 1).

Since also interleukin 6 plays a key role in the pathogenesis of RA, such cytokine was targeted by the bispecific nanobody ALX0061 that binds as well to human serum albumin, recruited to extend the construct half-life. In cynomolgus monkeys, ALX0061 induced a dose-dependent inhibition of IL-6-induced inflammatory parameters (125).

\section{NANOBODY APPLICATIONS IN INFECTIOUS DISEASES}

The development of new vaccines and of antibiotics effective on multi-resistant bacteria is difficult and time-consuming. In recent years, nanobodies with neutralizing toxin activity have been studied for the treatment of bacterial toxins, such as those produced by Clostridium difficile, Bacillus anthracis, ricin and anthrax. These accomplishments show that nanobodies represent an alternative anti-infection therapeutic opportunity against bacterial and viral outbreaks $(126,127)$ (Table 4).

\section{Acute Inflammation and Sepsis}

The lack of specific treatment for sepsis leads to the worldwide incidence of 31.5 million of cases and to 5.3 million deaths per year. Sepsis severity is associated with plasma levels of matrix metalloproteinase-8 (MMP8) and tumor necrosis factor receptor (TNFR1) and, therefore, the effect of a bispecific nanobody able to block simultaneously MMP8 and HTNFR1 was evaluated (135). The results obtained in mouse model indicated that the nanobodydependent neutralization of MMP8 and HTNFR1 had a beneficial effect in terms of survival rate. Different combinations of biparatopic nanobodies conferred 100\% survival upon prophylactic or up to 24 hour post-infection administration in pneumonia mouse models challenged with Pseudomonas aeruginosa (150).

\section{Viral Infection}

Viral infectious diseases have been one of the leading killers in the history of mankind. Influenza A virus is the main pathogen causing human influenza, it can infect a variety of animals and cause cross-species infection (151). Influenza virus neuraminidase (NA) plays an important role in the release and spread of the virus as well as in the cellular infection and consequently is a potentially interesting therapeutic target (152). Cardoso et al. (2014) isolated a set of anti-H5N1 NA nanobodies and generated bivalent molecules either connecting two single-domains with a flexible linker or by exploiting the dimerization properties of a mouse IgG2a-Fc domain fused to each single domain (153). The results showed that bivalent nanobodies had an in vitro antiviral potency 30 - to 240-fold higher than monovalent nanobodies and protected $\mathrm{BALB} / \mathrm{c}$ mice from $\mathrm{H} 5 \mathrm{~N} 1$ infections when used as a prophylactic therapy. Multimeric constructs were also conceived to protect simultaneously from different viruses. Specifically, Hultberg et al. (2011) prepared a trimeric construct linking nanobodies specific for H5N1 Influenza (able to neutralize both clade1 and 2), Respiratory Syncytial Virus and Rabies virus that protected from any of the three viruses (128). The authors also demonstrated that playing on the format (different bivalent and biparatopic combinations of single nanobodies), it was possible to increase the potency of the neutralizing anti-viral reagents and concluded that multimerization of nanobody fragments targeting multiple epitopes on viral trimeric spike proteins is a powerful tool for antiviral therapy with broader neutralization capacity. The trivalent nanobody construct ALX-0171, designed for the inhalation treatment of respiratory syncytial virus infection, had a remarkable capacity to reduce escape mutant selection and showed promising results in animal models $(154,155)$ but was finally unable to improve clinical course in patients with established infection in the lower respiratory tract (156). Based on the results of such Phase IIb dose-ranging study, the Sponsor decided to discontinue ALX-0171 trials.

Enterovirus A71 (EVA71) is a major cause of viral encephalitis and severe hand, foot, and mouth disease (HFMD) in young children worldwide. Neither preventive not therapeutic treatments are available for limiting EVA71 infection. Huang et al. (2020) isolated a nanobody (F1), which inhibited EVA71 infection both in vitro and in vivo. The neutralizing activity was 
TABLE 4 | Multivalent/bispecific nanobodies for infectious diseases.

\begin{tabular}{|c|c|c|c|c|c|}
\hline Nanobody & Disease & Target & Structure features & Year & Reference \\
\hline D3n(GS)2 & Respiratory & Fusion protein & Bivalent & 2011 & $(128)$ \\
\hline D3/E4 & Syncytial Virus & & Biparatopic & & \\
\hline C12 n(GS)2 & Rabies virus & Glycoprotein & Bivalent & 2011 & (128) \\
\hline $\mathrm{E} 8 / \mathrm{H} 7$ & & & Biparatopic & & \\
\hline C8 n(GS)2 & H5N1 Influenza & Hemagglutinin 5 & Bivalent/trivalent & 2011 & $(128)$ \\
\hline ARP1-ARP1 & Rotavirus & $\mathrm{RRV}$ & Bivalent & 2011 & (129) \\
\hline ARP3-ARP1 & & & Bispecific & & \\
\hline T5-V36 & Tetanus Toxin & TerC/Mac-1 & Bispecific & 2015 & $(130)$ \\
\hline JJX12 & Ricin Toxin & RTA/RTB & Bispecific & 2016 & $(131)$ \\
\hline $\mathrm{Ad} /$ & Bacillus anthracis & Lethal factor/edema factor & Bispecific & 2016 & (132) \\
\hline VNA2-PA & Lethal/edema toxin & & & & \\
\hline Liposomal Vhhs & HIV & gp120 & Multivalent monospecific & 2016 & (133) \\
\hline VUN401-Fc & HIV & CXCR4 & Bivalent monospecific & 2018 & $(134)$ \\
\hline Nb70-alb-14 & Acute Inflammation and Sepsis & TNFR1/MMP8 & Bivalent bispecific & 2018 & $(135)$ \\
\hline $\mathrm{NbF} 12-10$ & Androctonus australis hector scorpion venom toxins & Aahl/Aahll & Bispecific & 2018 & $(136)$ \\
\hline$V_{H} H-V_{H} H$ dimers & Clostridium difficile toxin B & CROPs domain & Bivalent & 2018 & $(137)$ \\
\hline $\mathrm{Nb} 113_{2}$ & Escherichia coli Shiga toxin & Stx2a & Bivalent & 2018 & (138) \\
\hline J3-2E7 & HIV & gp41/gp120 & Bivalent bispecific & 2019 & $(139)$ \\
\hline $\mathrm{Nb} 2 \mathrm{TCE} 49$ & Human toxocariasis & TES & Bivalent & 2019 & $(140)$ \\
\hline $\mathrm{F} 1 \times \mathrm{F} 1-\mathrm{hFc}$ & Hand, foot, and mouth disease (HFMD) & Enterovirus A71 & Tetravalent & 2020 & $(141)$ \\
\hline H11-D4-Fc & COVID-19 & SARS-CoV-2 spike RBD & Bivalent & 2020 & $(142)$ \\
\hline \multicolumn{6}{|l|}{$\mathrm{H} 11-\mathrm{H} 4-\mathrm{FC}$} \\
\hline $\mathrm{Nb}-\mathrm{FC}$ & COVID-19 & & Multivalent & 2020 & $(143)$ \\
\hline Cocktail nanobody & COVID-19 & & $\begin{array}{l}\text { Multivalent } \\
\text { Multi-epitope cocktail }\end{array}$ & 2020 & $(144)$ \\
\hline Nbs 20/21 & COVID-19 & SARS-CoV-2 spike RBD & Trivalent & 2020 & $(145)$ \\
\hline sACE2-anti-CD16 VHH & COVID-19 & $\mathrm{RBD} / \mathrm{CD} 16$ & bispecific & 2021 & $(146)$ \\
\hline $\mathrm{Nb} 15-\mathrm{NbH}-\mathrm{Nb} 15$ & COVID-19 & SARS-CoV-2 spike glycoprotein/HSA & Trivalent bispecific & 2021 & $(147)$ \\
\hline hlgG1FC-VHH & Bunyaviruses & $\mathrm{RVFV} / \mathrm{SBV}$ & Tetravalent bispecific & 2021 & $(148)$ \\
\hline aRBD-2-5; aRBD-2-7 & COVID-19 & $\mathrm{RBD}$ & Bispecific & 2021 & $(149)$ \\
\hline
\end{tabular}

improved when multivalent formats were used and the most effective constructs were the ones in which the structure geometry enabled to maximally exploit the avidity effect (141).

Gastroenteritis induced by rotavirus infection is a major health problem in development countries. Bispecific nanobody constructs targeting independent rotavirus epitopes were used to transform Lactobacilli. Next, Lactobacilli cultures were used to deliver the neutralizing nanobodies to the intestinal lumen and such posology showed high anti-virus efficiency (129).

\section{HIV-Dependent Immunodeficiency Syndrome}

Acquired immunodeficiency syndrome (AIDS) causes about 1.8 million AIDS-related deaths each year (157) and is caused by infection with HIV (Human Immunodeficiency Virus). HIV leads to extensive destruction of T-helper cells, macrophages, dendritic cells, and other cellular components associated with cell-mediated immunity, eventually leading to the destruction of the immune system. Consequently, the organism becomes the target of many opportunistic diseases (158). At the present, the effective antiretroviral therapy (HAART) renders HIV a chronic disease (159) but this treatment is expensive and has many adverse effects (160). Therefore, there is still an urgent demand for effective and low-cost treatment of HIV infection.

Experiments made with combinations of patient-derived HIV neutralizing antibodies targeting complementary epitopes demonstrated that the inhibition effect was increased when more virus epitopes were blocked contemporarily (161). A contribution to the effort of isolating antibodies with complementary characteristics was the method described by Koh et al. that allowed the recovery of nanobodies with distinct binding features (162). However, no further studies with multispecific constructs built using the selected binders were published, despite the encouraging results showing that nanobody homo- or heteromultimers could neutralize a wide array of virus subtype (163). A bivalent nanobody targeting the proximal external region of gp 120 had a neutralization capacity 20 times higher than the monovalent ligand (164) and a bispecific construct targeting gp41 and gp120 epitopes possessed a neutralizing potency up to 1400 -fold higher than the mixture of the individual nanobodies (139). Liposomes displaying nanobodies were also proposed to increase avidity, but the results were deceiving because the low nanobody density impaired the simultaneous binding to more than one target protein (133). More promising it seems the alternative of using neutralizing nanobodies displayed on the surface of Lactobacillus rhamnosus cells (165).

An alternative approach considered targeting the CXCR4 receptor that participates in the viral uptake (134). Bivalent constructs were constructed by linking nanobodies to a human IgG1 antibody Fc domain and were compared with their monovalent counterparts. The Nb-Fc constructs had higher binding affinity, blocked more efficiently the CXCR4-mediated HIV entry and induced ADCC- and CDC-mediated cell-death of 
CXCR4-overexpressing cells, a condition that renders such molecules attractive to treat also CXCR4-overexpressing tumors.

\section{SARS-CoV-2 Infection}

SARS-CoV-2 is a single-stranded RNA virus that belongs to the CoVs family. The receptor-binding domain (RBD) of the spike protein binds to the host cell surface receptor angiotensinconverting enzyme 2 (ACE2). Several anti-spike/anti-RBD neutralizing antibodies have been isolated from both patients and by in vitro selection, some of them have entered clinical trials and cocktails of ligands binding to different epitopes have been proposed to overcome resistance due to the virus mutations (127, 166). Multispecific antibody fragments are an alternative solution to prevent mutation-dependent resistance, as it has been already summarized in recent reviews (34, 127, 167). Since the research on anti-SARS-CoV-2 is particularly active and new publications appear constantly, here we report only those relevant to the subject of the present review and published in the first 2021 quarter.

Heterodimers formed by nanobodies recognizing independent epitopes and connected by fusion with the human Fc fragment exhibited the strongest RBD-binding affinity and neutralizing ability against SARS-CoV-2 pseudoviruses (143). In this case, the nanobodies were isolated from a naïve library but the same strategy of using nanobody-based Fc-dependent heterodimers to increase both the apparent affinity and the neutralizing activity of the immune reagents was successfully exploited by another group that used immunized alpaca as the source of the ligands (149). The recognized advantage of targeting independent epitopes was also used to change paradigm in the preparation of multivalent constructs: instead of assembling randomly isolated, not overlapping nanobodies, these were chosen according to the available structural information (168). This strategy enabled to design biparatopic constructs with apparent affinity in the pM range starting from nanobodies with 10-100 times lower affinities $(169,170)$.

The other actual acute problem posed by the pandemic is the emergency of virus variants. Specifically targeting the single mutations might be extremely demanding, but a recent work (171) demonstrated that it is possible to have a large array of neutralizing nanobodies specific for several independent epitopes of the conserved regions, the combined use of which should offer protection options even in the case of highly mutated virus forms.

\section{Anti-Toxin Nanobodies}

In the case of toxin infection, nanobodies have the pivotal advantage over IgG that most of them can be expressed as functional intrabodies and therefore can be directly produced inside host mammalian cells as a protective antidote. The toxin neutralizing capacity of a prophylactic gene therapy has been successfully demonstrated in the case of Bacillus anthracis infection, the causative agent of anthrax (132). The protective antigen (PA) is the common component of $B$. anthracis toxins. The sequences of two anti-PA nanobodies targeting two independent antigen epitopes were cloned in an adenovirus vector to produce a bispecific immunoreagent. Mice were injected with the vector and the resulting nanobody construct that accumulated in their sera protected the animals by infections with anthrax toxins and spores.

Clostridium difficile is a problematic nosocomial pathogen that can cause diarrhea, pseudomembrane colitis and even death due to the effect of the virulence factors TcdA and TcdB toxins (172). Monomeric nanobodies targeting different TcdB epitopes were incapable of preventing TcdB-induced cytotoxicity in cellbased assays, despite their very high-affinity. However, the toxic effect inhibition was achieved when nanobodies were prepared into Fc-dependent bivalent constructs (137).

Shiga toxin-producing Escherichia coli (STEC) are a subset of potentially lethal pathogens. Tandem repeats of nanobodies targeting the Shiga toxin-2a B subunit provided toxin neutralization capacity 100 times higher than the monovalent constructs (138). For the neutralization of tetanus neurotoxins, the best results were obtained by fusing an anti-toxin nanobody to another specific for Mac-1, a surface integrin receptor expressed on most innate immune cells that plays an essential role in the elimination of complement opsonized microorganisms (130). The bispecific construct allowed mice to survive a 10-fold lethal dose with respect to monomeric anti-toxin and outperformed a sheep anti-toxin polyclonal IgG. Another bispecific nanobody construct alleviated ricin toxin effects by promoting its aggregation and by modifying the dynamics of ricin uptake and its cellular trafficking (131).

Multivalent/multispecific nanobody constructs were also beneficially used for diagnostic goals. Bispecific nanobodies were used to construct an electrochemical biosensor to detect the scorpion venom toxins AahI and AahII (136). In the case of human toxocariasis, the most effective ELISA test was obtained using bivalent nanobodies for antigen capture (140). The Alternaria mycotoxin tenuazonic acid was conveniently detected with high sensitivity using a one-step bioluminescent enzyme immunoassay that required the bifunctional fusion formed by nanobody and nanoluciferase (173).

\section{NANOBODIES FOR FURTHER THERAPEUTIC APPLICATIONS}

Despite most of the applications for nanobody-based reagents were conceived for few specific research areas, their potential usefulness appears confirmed also in further fields (Table 5).

\section{Type 2 Diabetes Mellitus}

Type 2 diabetes mellitus is a chronic metabolic disorder disease characterized by hyperglycemia and associated comorbidities (179). Glucagon-like peptide-1 (GLP-1) plays an essential role in glucose homeostasis by binding to and activating the GLP-1 receptor but its extremely short half-life $(3 \mathrm{~min}$ ) limits the effect its therapeutic administration. Everestmab is a tri-functional construct developed to overcome this drawback. It is a fusion protein consisting of a mutated GLP-1, necessary for the biological activation of the GLP-1 receptor, an anti-GLP-1 nanobody suitable for the construct targeted delivery, and an 
TABLE 5 | Other multivalent/bispecific nanobodies with therapeutic potential.

\begin{tabular}{|c|c|c|c|c|c|}
\hline Nanobody & Disease & Target & Structure features & Year & Reference \\
\hline $\mathrm{FAF}-\mathrm{Nb}$ & Gelsolin amyloidosis & D187N/Y gelsolin/HSA & $\begin{array}{l}\text { Bivalent } \\
\text { Bispecific }\end{array}$ & 2014 & $(174)$ \\
\hline $\mathrm{Nb} 22-\mathrm{FAF}-\mathrm{Nb}$ & Gelsolin amyloidosis & C68/amyloidogenic gelsolin-fragment & $\begin{array}{l}\text { Bivalent } \\
\text { Bispecific }\end{array}$ & 2017 & $(175)$ \\
\hline Everestmab & Type 2 diabetes mellitus & GLP-1R/HSA & $\begin{array}{l}\text { Bivalent } \\
\text { Bispecific }\end{array}$ & 2020 & $(176)$ \\
\hline $\mathrm{VHH}-\mathrm{B} 11$ & Cardiovascular diseases & Low density lipoprotein cholesterol & Bivalent & 2020 & $(177)$ \\
\hline $\mathrm{BI}-\mathrm{X}$ & Retinal vascular diseases & VEGF/Ang-2/HSA & $\begin{array}{l}\text { Multivalent } \\
\text { Multi-specific }\end{array}$ & 2021 & $(178)$ \\
\hline
\end{tabular}

anti-HSA nanobody to prolong its circulation time of the construct to several days. Everestmab treatments produced promising results in animal models (176).

\section{Retinal Neovascular Diseases}

Neovascular age-related macular degeneration and diabetic retinopathy are major causes of visual impairment and blindness, requiring frequent intravitreal injections of antiangiogenesis biotherapeutics (180). The trispecific nanobody construct BI-X was designed for targeting simultaneously both the angiogenesis factors VEGF-A and Ang-2 and human albumin to increase the molecule half-life (178). BI-X showed superior efficacy and significant half-life extension when tested in cynomolgus monkeys after intravitreal injection. However, intravitreal injection is a burden for patients and has potential complications, such as infections and topic applications will be tested.

\section{Neurodegenerative Diseases}

Nanobodies have been highly used to study the structure and the development of protein aggregates involved in the progression of neurodegenerative diseases $(52,181-183)$. A recent review illustrates how multimeric constructs based on antibody fragments can be used as effective intrabodies (184) for retargeting antigen-antibody complexes. Specifically, nanobodies were engineered to favor PEST-dependent degradation of $\alpha$ Synuclein $(\alpha-$ Syn $)(185,186)$. Nanobody bioconjugates were also successfully used as imaging probes able to cross the blood brain barrier and label amyloid-beta deposits after intravenous injection (187) as well as to functionalize gadolinium-based nanoparticles that allowed the visualization of amyloid fibril deposits in pathological tissues (188). Anti- $\alpha$-Syn nanobodies fused to a fluorescent probe enabled to monitor the cytosolic presence of the antigen and to reveal the presence of transmittable $\alpha$ Syn in human cerebrospinal fluid (189).

Gelsolin amyloidosis, also known as familial amyloidosis of the Finnish type, is an autosomal dominantly inherited systemic disorder with ophthalmologic, neurologic, and dermatologic symptoms (190). A single point mutation (D187N) results in a pathological proteolytic cascade with the formation of amyloidogenic peptides which aggregate in multiple tissues and cause disease-associated symptoms. Nanobodies exclusively selective for one of the amyloidogenic fragment, but not for the wild type protein, acted as molecular chaperones and mitigated the aggregation process (174). Their effect in vivo was significantly improved when the animals were treated with a bispecific molecule obtained by coupling the anti-gelsolin nanobody with an anti-albumin nanobody. The same group demonstrated the protective effect of such construct when it was directly expressed by mutant mice that underwent adenovirus-based gene therapy (175).

\section{Others}

A nanobody inhibiting the proprotein convertase subtilisin/ kexin type 9 (PCSK9) was expressed fused to an Fc domain and effectively reduced the production of low density lipoprotein (LDL) and cholesterol in a rat model (177). The results were comparable to those obtained with the approved monoclonal evolocumab but at extremely lower production costs.

The bispecific nanobody ALX-0962 that targets both IgE and human serum albumin can neutralize soluble $\operatorname{IgE}$ as well as displace preformed IgE-FceRI complexes and therefore was considered for the treatment of allergic asthma (191).

\section{DISCUSSION}

Since Nisonoff and his colleagues proposed the concept of bispecific antibody 60 years ago, therapeutic bsAbs have made great progresses (192). At the present, over 85 bsAbs are progressing through clinical development for a wide variety of indications (193). The most attractive feature of BsAbs is that they have features and provide effects that are not present in a simple combination of single antibodies, such as increased avidity and selectivity. Furthermore, by targeting multiple molecular targets simultaneously, multi-specific antibodies can block independent signal pathways, a condition that contributes effectively to prevent drug resistance and immune escape. For instance, targeting simultaneously EGFR and VEGFR2 by means of a bispecific construct composed by fragments of the parental IgGs cetuximab and ramucirumab was effective in inhibiting EGFR-dependent tumor growth and VEGFR2 angiogenic pathway in a mouse model of Triple Negative Breast Cancer (194), whereas a bispecific antibodies targeting TGF- $\beta$ and PDL1 showed a superior anti-tumor effect with respect to monotherapy due to enhanced anti-tumor immune response in multiple in vivo models (195).

Nowadays, nanobodies are regarded as an alternative to monoclonal antibodies because they overcome some of the IgG drawbacks, such as their low penetration in solid tumors and 
tissues, the difficulty to control their functionalization process and their elevated production costs in mammalian cells (15). Nanobodies small dimension allows deeperpenetration in solid tumors with respect to IgGs the effect of which is usually limited to the superficial cells. On the other hand, their limited mass favors also a rapid kidney filtration with consequent very short circulation half-life. This represents an advantage for in vivo imaging because rapidly reduces the background signal but it is the major shortcoming for therapeutic applications. However, the recombinant nature of nanobodies can be exploited to produce fusions with relevant proteins and tags that possess reduced clearance and even additional useful functions such as fluorescence or cytotoxicity or enable the building of multivalent and multi-specific constructs with largely diversified formats (10, 196-198). Multi-specific nanobodies retain at least part of the advantages of nanobodies, providing a mass that is still significantly smaller than IgGs and the capacity of targeting hidden epitopes by means of their protruding paratopes. Furthermore, their in vivo half-life can be fine-tuned according to the application needs (199). It must be also considered that nanobody biophysical features allow their administration via delivery routes that are not accessible to conventional IgGs. In addition to subcutaneous and intravenous injections, nanobodies can be nebulized directly into the respiratory tract (156), taken orally for gut treatment (165) and topically for ophthalmic applications. The PubMed data indicated that sixty research papers/year dealing with multi-valent/multi-specific nanobodies, half of them dedicated to cancer research, were published in the last two years (Figure 3). The research output indicates that multivalent and multi-specific constructs are more effective that their corresponding monomers. This evidence was confirmed any time that the monovalent and multivalent formats were compared, with no exception and independently on the strategies used to obtain multivalent structures. Also, nanobody derivatization with enzymes, dyes, chelators and other functional tags resulted in reliable and effective immunoreagents. In this case, the decisive advantage with respect to $\operatorname{IgG}$ was that the derivatization process was controlled, namely $1: 1$ and at a specific residue. This condition avoids the generation of heterogeneous populations of reagents characterized by different number of added functions at different residues, as detected when lysine amino groups are used (196).

Nanobodies are not particularly immunogenic and different humanization strategies have been conceived $(86,200)$ and such condition might simplify the clinical trials of nanobody-derived medicaments. Caplacizumab was the first nanobody-based approved drug (58) but despite several multivalent or multispecific nanobodies entered clinical trials, so far none has been approved (201). Companies usually do not divulgate the reasons of clinical trial failures but we can argue that these are the result of several factors. The delivery kinetic of such molecules can be affected by single patient proteome profile and they can show

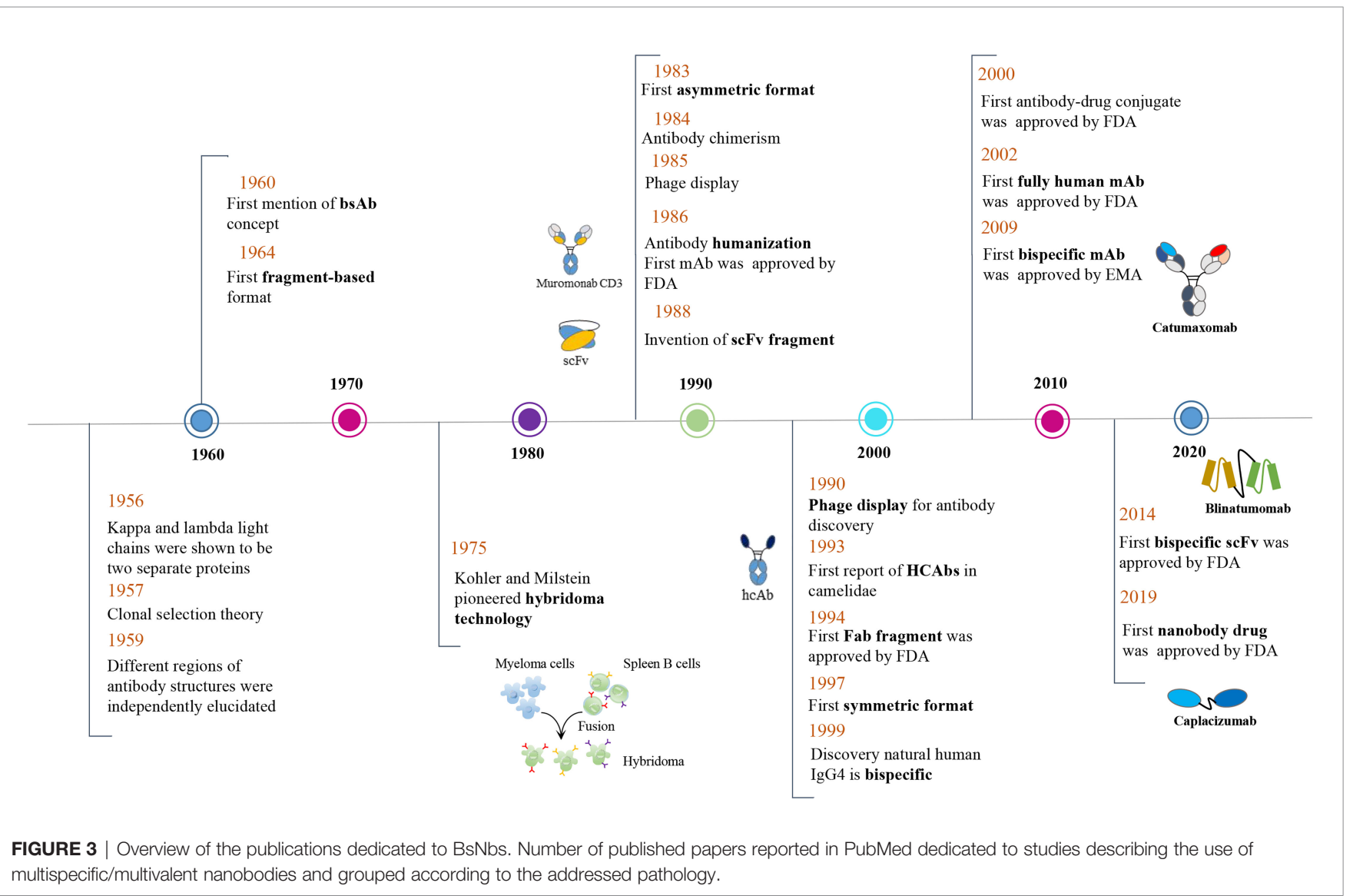


higher immunogenicity due to the creation of new epitopes corresponding to the linking sequences. Furthermore, such complex molecular structures require the precise threedimensional positioning of the single domains to achieve cooperative interaction with the antigen but so far there is no single evidence that a bispecific antibody could simultaneously bind to both epitopes in vivo. More probably, the generally observed higher efficacy of bispecific antibodies over treatments with monospecific antibodies or combination of them is due to an avidity effect allowed by the co-presence of both target epitopes in the same environment. Therefore, it will be necessary to further improve the structure design of multidomain binders by calculating the optimal distance between the paratopes in a way that enables the simultaneous binding to their corresponding epitopes. The research aimed at the high-resolution mapping of the receptors on the cell surface has provided meaningful information relatively to cluster density and composition $(93,202)$. These data are the base on which the next generation of multispecific antibodies will be probably designed. In this perspective, nanobody short sequence represents a decisive advantage because the computing requirements for their modeling are extremely less expensive than those necessary for larger binders. Computer-aided nanobody design technology has strongly improved in the last few years $(86,203-208)$ and will be more and more reliable for providing solutions also to these challenges.

Altogether, the accumulated experimental data and the available tools suggest that multimeric and functionalized molecules built using nanobodies will become a major component of future diagnostic and therapeutic reagents.

\section{DATA AVAILABILITY STATEMENT}

The original contributions presented in the study are included in the article/supplementary material. Further inquiries can be directed to the corresponding authors.

\section{AUTHOR CONTRIBUTIONS}

$\mathrm{HH}, \mathrm{AM}, \mathrm{JW}$, and GK contributed to the conception of this review. JW and GK wrote the first draft of the manuscript. HY is responsible for literature retrieval. $\mathrm{HH}, \mathrm{AM}, \mathrm{JW}, \mathrm{GK}$, and $\mathrm{HY}$ wrote sections of the manuscript. AM and $\mathrm{HH}$ supervise the project administration. All authors contributed to the article and approved the submitted version.

\section{FUNDING}

The present study was supported by grants from the National Key Research and Development Project (Grant No. 2019YFA0905600); the Science and Technology Program of Tianjin, China (Grant No. 19YFSLQY00110), the Major State Basic Research Development Program of the Natural Science Foundation of Shandong Province in China (Grant No. ZR2020ZD11), and by the grant ARRS/PA-0107 provided by the Javna Agencija za Raziskovalno Dejavnost Republike Slovenije. We thank Shaoxing "MingShiZhiXiang" Meritocrat Project and Program of Introducing Talents of Discipline to University Ministry of Education, China - 111 Project (Grant No. BP0618007) for its support.

\section{REFERENCES}

1. Kim K, Khang D. Past, Present, and Future of Anticancer Nanomedicine. Int J Nanomed (2020) 15:5719-43. doi: 10.2147/ijn.S254774

2. Redman JM, Hill EM, AlDeghaither D, Weiner LM. Mechanisms of Action of Therapeutic Antibodies for Cancer. Molecular Immunology. Mol Immunol (2015) 67:28-45. doi: 10.1016/j.molimm.2015.04.002

3. Kintzing JR, Interrante MVF, Cochrane JR. Emerging Strategies for Developing Next-Generation Protein Therapeutics for Cancer Treatment. Trends Pharmacol Sci (2016) 37:993-1008. doi: 10.1016/ j.tips.2016.10.005

4. Gautier V, Boumeester AJ, Loessl P, Heck AJR. Lysine Conjugation Properties in Human IgGs Studied by Integrating High-Resolution Native Mass Spectrometry and Bottom-Up Proteomics. Proteomics (2015) 15:2756-65. doi: 10.1002/pmic.201400462

5. Clackson T, Hoogenboom HR, Griffiths AD, Winter G. Making Antibody Fragments Using Phage Display Libraries. Nature (1991) 352:624-8. doi: $10.1038 / 352624 \mathrm{a} 0$

6. Pini A, Bracci L. Phage Display of Antibody Fragments. Curr Protein Pept Sci (2000) 1:155-69. doi: 10.2174/1389203003381397

7. Steeland S, Vandenbroucke RE, Libert C. Nanobodies as Therapeutics: Big Opportunities for Small Antibodies. Drug Discovery Today (2016) 21:1076113. doi: 10.1016/j.drudis.2016.04.003

8. Jovcevska I, Muyldermans S. The Therapeutic Potential of Nanobodies. Biodrugs (2020) 34:11-26. doi: 10.1007/s40259-019-00392-z

9. Liu Y, Huang H. Expression of Single-Domain Antibody in Different Systems. Appl Microbiol Biotechnol (2018) 102:539-51. doi: 10.1007/ s00253-017-8644-3

10. de Marco A. Recombinant Expression of Nanobodies and NanobodyDerived Immunoreagents. Protein Expr Purif (2020) 172:105645. doi: 10.1016/j.pep.2020.105645

11. Devoogdt N, Xavier C, Hernot S, Vaneycken I, D'Huyvetter M, De Vos J, et al. Molecular Imaging Using Nanobodies: A Case Study. Methods Mol Biol (Clifton NJ) (2012) 911:559-67. doi: 10.1007/978-1-61779-968-6_35

12. Chanier T, Chames P. Nanobody Engineering: Toward Next Generation Immunotherapies and Immunoimaging of Cancer. Antibodies (2019) 8:13. doi: 10.3390/antib8010013

13. Suurs FV, Lub-de Hooge MN, de Vries EGE, de Groot DJA. A Review of Bispecific Antibodies and Antibody Constructs in Oncology and Clinical Challenges. Pharmacol Ther (2019) 201:103-19. doi: 10.1016/j.pharmthera.2019.04.006

14. Chen W, Yuan Y, Jiang X. Antibody and Antibody Fragments for Cancer Immunotherapy. J Control Release (2020) 328:395-406. doi: 10.1016/ j.jconrel.2020.08.021

15. Bathula NV, Bommadevara H, Hayes JM. Nanobodies: The Future of Antibody-Based Immune Therapeutics. Cancer Biother Radiopharm (2021) 36:109-22. doi: 10.1089/cbr.2020.3941

16. Yang EY, Shah K. Nanobodies: Next Generation of Cancer Diagnostics and Therapeutics. Front Oncol (2020) 10:1182. doi: 10.3389/fonc.2020.01182

17. Tolmachev V, Orlova A, Sorensen J. The Emerging Role of Radionuclide Molecular Imaging of HER2 Expression in Breast Cancer. Semin Cancer Biol (2021) 72:S1044-579X(20)30210-8. doi: 10.1016/j.semcancer.2020.10.005

18. Kang G, Hu M, Ren H, Wang J, Cheng X, Li R, et al. VHH212 Nanobody Targeting the Hypoxia-Inducible Factor 1alpha Suppresses Angiogenesis and Potentiates Gemcitabine Therapy in Pancreatic Cancer In Vivo. Cancer Biol Med (2021) 18:772-87. doi: 10.20892/j.issn.2095-3941.2020.0568. j.issn.2095-3941.2020.0568. 
19. Ding L, Tian C, Feng S, Fida G, Zhang C, Ma Y, et al. Small Sized EGFR1 and HER2 Specific Bifunctional Antibody for Targeted Cancer Therapy. Theranostics (2015) 5:378-98. doi: 10.7150/thno.10084

20. Zhu Y, Bassoff N, Reinshagen C, Bhere D, Nowicki MO, Lawler SE, et al. BiSpecific Molecule Against EGFR and Death Receptors Simultaneously Targets Proliferation and Death Pathways in Tumors. Sci Rep (2017) 7:111. doi: 10.1038/s41598-017-02483-9

21. You F, Wang Y, Jiang L, Zhu X, Chen D, Yuan L, et al. A Novel CD7 Chimeric Antigen Receptor-Modified NK-92MI Cell Line Targeting T-Cell Acute Lymphoblastic Leukemia. Am J Cancer Res (2019) 9:64-+.

22. De Munter S, Ingels J, Goetgeluk G, Bonte S, Pille M, Weening K, et al. Nanobody Based Dual Specific CARs. Int J Mol Sci (2018) 19:1-11. doi: 10.3390/ijms19020403

23. de Bruin RCG, Veluchamy JP, Lougheed SM, Schneiders FL, Lopez-Lastra S, Lameris R, et al. A Bispecific Nanobody Approach to Leverage the Potent and Widely Applicable Tumor Cytolytic Capacity of V Gamma 9V Delta 2-T Cells. Oncoimmunology (2018) 7:1-37. doi: 10.1080/2162402x.2017.1375641

24. Albert S, Arndt C, Koristka S, Berndt N, Bergmann R, Feldmann A, et al. From Mono- to Bivalent: Improving Theranostic Properties of Target Modules for Redirection of UniCAR T Cells Against EGFR-Expressing Tumor Cells In Vitro and In Vivo. Oncotarget (2018) 9:25597-616. doi: 10.18632/oncotarget. 25390

25. Nikkhoi SK, Rahbarizadeh F, Ranjbar S, Khaleghi S, Farasat A. Liposomal Nanoparticle Armed With Bivalent Bispecific Single-Domain Antibodies, Novel Weapon in HER2 Positive Cancerous Cell Lines Targeting. Mol Immunol (2018) 96:98-109. doi: 10.1016/j.molimm.2018.01.010

26. Schutze K, Petry K, Hambach J, Schuster N, Fumey W, Schriewer L, et al. CD38-Specific Biparatopic Heavy Chain Antibodies Display Potent Complement-Dependent Cytotoxicity Against Multiple Myeloma Cells. Front Immunol (2018) 9:2553. doi: 10.3389/fimmu.2018.02553

27. Li Y, Zhou C, Li J, Liu J, Lin L, Li L, et al. Single Domain Based Bispecific Antibody, Muc1-Bi-1, and Its Humanized Form, Muc1-Bi-2, Induce Potent Cancer Cell Killing in Muc1 Positive Tumor Cells. PloS One (2018) 13:1-14. doi: 10.1371/journal.pone.0191024

28. Sadeghi A, Behdani M, Muyldermans S, Habibi-Anbouhi M, KazemiLomedasht F. Development of a Mono-Specific Anti-VEGF Bivalent Nanobody With Extended Plasma Half-Life for Treatment of Pathologic Neovascularization. Drug Test Anal (2020) 12:92-100. doi: 10.1002/dta.2693

29. de Weerdt I, Lameris R, Ruben JM, de Boer R, Kloosterman J, King LA, et al. A Bispecific Single-Domain Antibody Boosts Autologous Vgamma9Vdelta2-T Cell Responses Toward CD1d in Chronic Lymphocytic Leukemia. Clin Cancer Res (2021) 27:1744-55. doi: 10.1158/1078-0432.Ccr-20-4576

30. Zhao Y, Li Y, Wu X, Li L, Liu J, Wang Y, et al. Identification of Anti-CD16a Single Domain Antibodies and Their Application in Bispecific Antibodies. Cancer Biol Ther (2020) 21:72-80. doi: 10.1080/15384047.2019.1665953

31. He X, Feng Z, Ma J, Ling S, Cao Y, Gurung B, et al. Bispecific and Split CAR T Cells Targeting CD13 and TIM3 Eradicate Acute Myeloid Leukemia. Blood (2020) 135:713-23. doi: 10.1182/blood.2019002779

32. Ma L, Zhu M, Gai J, Li G, Chang Q, Qiao P, et al. Preclinical Development of a Novel CD47 Nanobody With Less Toxicity and Enhanced Anti-Cancer Therapeutic Potential. J Nanobiotechnol (2020) 18:12-27. doi: 10.1186/ s12951-020-0571-2

33. Pedersen DV, Roesner T, Hansen AG, Andersen KR, Thiel S, Andersen GR, et al. Recruitment of Properdin by Bi-Specific Nanobodies Activates the Alternative Pathway of Complement. Mol Immunol (2020) 124:200-10. doi: 10.1016/j.molimm.2020.06.005

34. Nikooharf A, Arezumand R, Mansouri K, Khoshi AH, Namdar Ahmadabad H. Development of a Recombinant Monospecific Anti-PLGF Bivalent Nanobody and Evaluation of It in Angiogenesis Modulation. Mol Biotechnol (2020) 62:580-8. doi: 10.1007/s12033-020-00275-7

35. Xu Z, Qiu C, Wen B, Wang S, Zhu L, Zhao L, et al. A Bispecific Nanobody Targeting the Dimerization Interface of Epidermal Growth Factor Receptor: Evidence for Tumor Suppressive Actions In Vitro and In Vivo. Biochem Biophys Res Commun (2021) 548:78-83. doi: 10.1016/j.bbrc.2021.02.059

36. Vallera DA, Oh F, Kodal B, Hinderlie P, Geller MA, Miller JS, et al. A HER2 Tri-Specific NK Cell Engager Mediates Efficient Targeting of Human Ovarian Cancer. Cancers (2021) 13:3994-4004. doi: 10.3390/ cancers 13163994
37. Fan JS, Zhuang XL, Yang XY, Xu YC, Zhou Z, Pan LQ, et al. A Multivalent Biparatopic EGFR-Targeting Nanobody Drug Conjugate Displays Potent Anticancer Activity in Solid Tumor Models. Signal Transduct Target Ther (2021) 6:1-3. doi: 10.1038/s41392-021-00666-5

38. Ma LL, Gai JW, Qiao P, Li YF, Li XF, Zhu M, et al. A Novel Bispecific Nanobody With PD-L1/TIGIT Dual Immune Checkpoint Blockade. Biochem Biophys Res Commun (2020) 531:144-51. doi: 10.1016/ j.bbrc.2020.07.072

39. Toffoli EC, Sheikhi A, Lameris R, King LA, van Vliet A, Walcheck B, et al. Enhancement of NK Cell Antitumor Effector Functions Using a Bispecific Single Domain Antibody Targeting CD16 and the Epidermal Growth Factor Receptor. Cancers (2021) 13:5446-68. doi: 10.3390/cancers13215446

40. van Faassen H, Jo DH, Ryan S, Lowden MJ, Raphael S, MacKenzie CR, et al. Incorporation of a Novel CD16-Specific Single-Domain Antibody Into Multispecific Natural Killer Cell Engagers With Potent ADCC. Mol Pharm (2021) 18:2375-84. doi: 10.1021/acs.molpharmaceut.1c00208

41. Wang HX, Wang LY, Li YN, Li GQ, Zhang XC, Jiang D, et al. NanobodyArmed T Cells Endow CAR-T Cells With Cytotoxicity Against Lymphoma Cells. Cancer Cell Int (2021) 21:450-62. doi: 10.1186/s12935-021-02151-z

42. Xenaki KT, Dorrestijn B, Muns JA, Adamzek K, Doulkeridou S, Houthoff H, et al. Homogeneous Tumor Targeting With a Single Dose of HER2-Targeted Albumin-Binding Domain-Fused Nanobody-Drug Conjugates Results in Long-Lasting Tumor Remission in Mice. Theranostics (2021) 11:5525-38. doi: $10.7150 /$ thno. 57510

43. Djender S, Schneider A, Beugnet A, Crepin R, Desrumeaux KE, Romani C, et al. Bacterial Cytoplasm as an Effective Cell Compartment for Producing Functional VHH-Based Affinity Reagents and Camelidae IgG-Like Recombinant Antibodies. Microb Cell Fact (2014) 13:140-50. doi: 10.1186/ s12934-014-0140-1

44. Debie P, Devoogdt N, Hernot S. 9 Targeted Nanobody-Based Molecular Tracers for Nuclear Imaging and Image-Guided Surgery. Antibodies (2019) 8:1-21. doi: $10.3390 /$ antib8010012

45. de Marco A. Perspectives Offered by Single-Domain Antibodies in Clinical Diagnostic of Pediatric Tumors. Curr Med Chem (2013) 20:2188-94. doi: 10.2174/0929867311320170004

46. Pruszynski M, Koumarianou E, Vaidyanathan G, Revets H, Devoogdt N, Lahoutte T, et al. Targeting Breast Carcinoma With Radioiodinated AntiHER2 Nanobody. Nucl Med Biol (2013) 40:52-9. doi: 10.1016/ j.nucmedbio.2012.08.008

47. Keyaerts M, Xavier C, Heemskerk J, Devoogdt N, Everaert H, Ackaert C, et al. Phase I Study of Ga-68-HER2-Nanobody for PET/CT Assessment of HER2 Expression in Breast Carcinoma. J Nucl Med (2016) 57:27-33. doi: $10.2967 /$ inumed.115.162024

48. Liu Q, Jiang L, Li K, Li H, Lv G, Lin J, et al. Immuno-PET Imaging of Ga-68Labeled Nanobody Nb109 for Dynamic Monitoring the PD-L1 Expression in Cancers. Cancer Immunol Immunother (2021) 70:1721-33. doi: 10.1007/ s00262-020-02818-y

49. Zinzani PL, Stefoni V, Alinari L, Vianelli N, Baccarani M. Rituximab in Heavily Pretreated Cutaneous B-Cell Lymphoma. Leuk Lymphoma (2003) 44:1637-8. doi: 10.1080/1042819031000104024

50. Wang Z, Wu Z, Liu Y, Han W. New Development in CAR-T Cell Therapy. J Hematol Oncol (2017) 10:53-64. doi: 10.1186/s13045-017-0423-1

51. Gardner R, Wu D, Cherian S, Fang M, Hanafi L-A, Finney O, et al. Acquisition of a CD19-Negative Myeloid Phenotype Allows Immune Escape of MLL-Rearranged B-ALL From CD19 CAR-T-Cell Therapy. Blood (2016) 127:2406-10. doi: 10.1182/blood-2015-08-665547

52. Abskharon RNN, Giachin G, Wohlkonig A, Soror SH, Pardon E, Legname G, et al. Probing the N-Terminal Beta-Sheet Conversion in the Crystal Structure of the Human Prion Protein Bound to a Nanobody. J Am Chem Soc (2014) 136:937-44. doi: 10.1021/ja407527p

53. Afzali A, Chiorean M. Combination of Biologic Agents in the Management of Severe Refractory Crohn's Disease: A Case Report of Concomitant Treatment With Vedolizumab and Adalimumab. Am J Gastroenterol (2016) 111:S823-4. doi: 10.14309/00000434-201610001-01725

54. Rozenbaum M, Meir A, Aharony Y, Itzhaki O, Schachter J, Bank I, et al. Gamma-Delta CAR-T Cells Show CAR-Directed and Independent Activity Against Leukemia. Front Immunol (2020) 11:1347. doi: 10.3389/ fimmu.2020.01347 
55. Chao MP, Alizadeh AA, Tang C, Jan M, Weissman-Tsukamoto R, Zhao F, et al. Therapeutic Antibody Targeting of CD47 Eliminates Human Acute Lymphoblastic Leukemia. Cancer Res (2011) 71:1374-84. doi: 10.1158/00085472.Can-10-2238

56. Sebastian M, Schmittel A, Friccius-Quecke H, Kanniess F, Wiewrodt R, Lindhofer H, et al. Treatment of Non-Small Cell Lung Cancer (NSCLC) Patients With the Trifunctional Bispecific Antibody Catumaxomab (Removab (R)) (Anti-EpCAM X Anti-CD3: Results of a Phase I Study. Lung Cancer (2005) 49:S376-S. doi: 10.1016/s0169-5002(05)81467-9

57. Topp MS, Kufer P, Goekbuget N, Goebeler M, Klinger M, Neumann S, et al. Targeted Therapy With the T-Cell-Engaging Antibody Blinatumomab of Chemotherapy-Refractory Minimal Residual Disease in B-Lineage Acute Lymphoblastic Leukemia Patients Results in High Response Rate and Prolonged Leukemia-Free Survival. J Clin Oncol (2011) 29:2493-8. doi: 10.1200/jco.2010.32.7270

58. Scully M, Cataland SR, Peyvandi F, Coppo P, Knobl P, Hovinga JAK, et al. Caplacizumab Treatment for Acquired Thrombotic Thrombocytopenic Purpura. N Engl J Med (2019) 380:335-46. doi: 10.1056/NEJMoa1806311

59. Eto T, Akashi K, Harada M, Shibuya T, Takamatsu Y, Teshima T, et al. Biological Characteristics of CD7 Positive Acute Myelogenous Leukaemia. Br J Haematol (1992) 82:508-14. doi: 10.1111/j.1365-2141.1992.tb06460.x

60. Tang J, Li J, Zhu X, Yu Y, Chen D, Yuan L, et al. Novel CD7-Specific Nanobody-Based Immunotoxins Potently Enhanced Apoptosis of CD7Positive Malignant Cells. Oncotarget (2016) 7:34070-83. doi: 10.18632/ oncotarget.8710

61. Yu Y, Li J, Zhu X, Tang X, Bao Y, Sun X, et al. Humanized CD7 NanobodyBased Immunotoxins Exhibit Promising Anti-T-Cell Acute Lymphoblastic Leukemia Potential. Int J Nanomed (2017) 12:1969-83. doi: 10.2147/ ijn.S127575

62. de Weers M, Tai Y-T, van der Veer MS, Bakker JM, Vink T, Jacobs DCH, et al. Daratumumab, a Novel Therapeutic Human CD38 Monoclonal Antibody, Induces Killing of Multiple Myeloma and Other Hematological Tumors. J Immunol (2011) 186:1840-8. doi: 10.4049/jimmunol.1003032

63. Jasinski M, Basak GW, Jedrzejczak WW. Perspectives for the Use of CAR-T Cells for the Treatment of Multiple Myeloma. Front Immunol (2021) 12:632937. doi: 10.3389/fimmu.2021.632937

64. Zhang Y, Zhang C, Zhou J, Zhang J, Chen X, Chen J, et al. Case Report: Reversible Neurotoxicity and a Clinical Response Induced by BCMADirected Chimeric Antigen Receptor T Cells Against Multiple Myeloma With Central Nervous System Involvement. Front Immunol (2021) 12:552429. doi: 10.3389/fimmu.2021.552429

65. Neufeld G, Tessler S, Gitay-Goren H, Cohen T, Levi BZ. Vascular Endothelial Growth Factor and Its Receptors. Cytokine Growth Factor Rev (1994) 5:89-97. doi: 10.1016/0955-2235(94)90019-1

66. De Falco S. The Discovery of Placenta Growth Factor and Its Biological Activity. Exp Mol Med (2012) 44:1-9. doi: 10.3858/emm.2012.44.1.025

67. Albonici L, Giganti MG, Modesti A, Manzari V, Bei R. Multifaceted Role of the Placental Growth Factor (PlGF) in the Antitumor Immune Response and Cancer Progression. Int J Mol Sci (2019) 20:1-32. doi: 10.3390/ ijms 20122970

68. van de Water JAJM, Bagci-Onder T, Agarwal AS, Wakimoto H, Roovers RC, Zhu Y, et al. Therapeutic Stem Cells Expressing Variants of EGFR-Specific Nanobodies Have Antitumor Effects. P Natl Acad Sci USA (2012) 109:16642-7. doi: 10.1073/pnas.1202832109

69. Papadopoulos KP, Isaacs R, Bilic S, Kentsch K, Huet HA, Hofmann M, et al. Unexpected Hepatotoxicity in a Phase I Study of TAS266, a Novel Tetravalent Agonistic Nanobody(A (R)) Targeting the DR5 Receptor. Cancer Chemother Pharmacol (2015) 75:887-95. doi: 10.1007/s00280-015-2712-0

70. Kovalchuk B, Berghoff AS, Karreman MA, Frey K, Piechutta M, Fischer M, et al. Nintedanib and a Bi-Specific Anti-VEGF/Ang2 Nanobody Selectively Prevent Brain Metastases of Lung Adenocarcinoma Cells. Clin Exp Metastasis (2020) 37:637-48. doi: 10.1007/s10585-020-10055-x

71. Pendharkar D, Ausekar BV, Gupta S. Molecular Biology of Lung CancerA Review. India J Surg Oncol (2013) 4:120-4. doi: 10.1007/s13193-013-0213-3

72. Zhang Q, Wu L, Liu S, Chen Q, Zeng L, Chen X. Targeted Nanobody Complex Enhanced Photodynamic Therapy for Lung Cancer by Overcoming Tumor Microenvironment. Cancer Cell Int (2020) 20:570-86. doi: 10.1186/s12935-020-01613-0
73. Tabtimmai L, Suphakun P, Srisook P, Kiriwan D, Phanthong S, Kiatwuthinon P, et al. Cell-Penetrable Nanobodies (Transbodies) That Inhibit the Tyrosine Kinase Activity of EGFR Leading to the Impediment of Human Lung Adenocarcinoma Cell Motility and Survival. J Cell Biochem (2019) 120:18077-87. doi: 10.1002/jcb.29111

74. Franchino F, Ruda R, Soffietti R. Mechanisms and Therapy for Cancer Metastasis to the Brain. Front Oncol (2018) 8:161. doi: 10.3389/ fonc.2018.00161

75. Manabe T, Yasuda H, Terai H, Kagiwada H, Hamamoto J, Ebisudani T, et al. IGF2 Autocrine-Mediated IGF1R Activation Is a Clinically Relevant Mechanism of Osimertinib Resistance in Lung Cancer. Mol Cancer Res (2020) 18:549-59. doi: 10.1158/1541-7786.Mcr-19-0956

76. Yin W, Zhao Y, Kang X, Zhao P, Zhao X, Mo X, et al. BBB-Penetrating Codelivery Liposomes Treat Brain Metastasis of Non-Small Cell Lung Cancer With EGFR(T790M) Mutation. Theranostics (2020) 10:6122-35 doi: 10.7150/thno.42234

77. Wang H, Meng A-M, Li S-H, Zhou X-L. A Nanobody Targeting Carcinoembryonic Antigen as a Promising Molecular Probe for NonSmall Cell Lung Cancer. Mol Med Reps (2017) 16:625-30. doi: 10.3892/ mmr.2017.6677

78. Rakovich TY, Mahfoud OK, Mohamed BM, Prina-Mello A, CrosbieStaunton K, Van den Broeck T, et al. Highly Sensitive Single Domain Antibody-Quantum Dot Conjugates for Detection of HER2 Biomarker in Lung and Breast Cancer Cells. ACS Nano (2014) 8:5682-95. doi: 10.1021/ nn500212h

79. Van Damme H, Dombrecht B, Kiss M, Roose H, Allen E, Van Overmeire E, et al. Therapeutic Depletion of CCR8(+) Tumor-Infiltrating Regulatory T Cells Elicits Antitumor Immunity and Synergizes With Anti-PD-1 Therapy. Immunother Cancer (2021) 9:1-16. doi: 10.1136/jitc-2020-001749

80. Tian B, Wong WY, Uger MD, Wisniewski P, Chao H. Development and Characterization of a Camelid Single Domain Antibody-Urease Conjugate That Targets Vascular Endothelial Growth Factor Receptor 2. Front Immunol (2017) 8:956. doi: 10.3389/fimmu.2017.00956

81. Wang D-Y, Jiang Z, Ben-David Y, Woodgett JR, Zacksenhaus E. Molecular Stratification Within Triple-Negative Breast Cancer Subtypes. Sci Rep (2019) 9:19107-17. doi: 10.1038/s41598-019-55710-w

82. Yarden Y. Biology of HER2 and Its Importance in Breast Cancer. Oncology (2001) 61:1-13. doi: 10.1159/000055396

83. Moghimi SM, Rahbarizadeh F, Ahmadvand D, Parhamifar L. Heavy Chain Only Antibodies: A New Paradigm in Personalized HER2+ Breast Cancer Therapy. BioImpacts (2013) 3:1-4. doi: 10.5681/bi.2013.009

84. Bubalo J. HER2 Receptor Antagonist-Associated Cardiotoxicity. J Hematol Oncol Pharm (2016) 6:85-8. doi: 10.1007/s10549-019-05303-y

85. Schmitz KR, Ferguson KM. Interaction of Antibodies With ErbB Receptor Extracellular Regions. Exp Cell Res (2009) 315:659-70. doi: 10.1016/ j.yexcr.2008.10.008

86. Soler MA, Medagli B, Wang J, Oloketuyi S, Bajc G, Huang H, et al. Effect of Humanizing Mutations on the Stability of the Llama Single-Domain Variable Region. Biomolecules (2021) 11:163-73. doi: 10.3390/ biom11020163

87. Vaneycken I, Devoogdt N, Van Gassen N, Vincke C, Xavier C, Wernery U, et al. Preclinical Screening of Anti-HER2 Nanobodies for Molecular Imaging of Breast Cancer. FASEB J (2011) 25:2433-46. doi: 10.1096/fj.10-180331

88. Zhou Z, Vaidyanathan G, McDougald D, Kang CM, Balyasnikova I, Devoogdt N, et al. Fluorine-18 Labeling of the HER2-Targeting SingleDomain Antibody 2rs15d Using a Residualizing Label and Preclinical Evaluation. Mol Imaging Biol (2017) 19:867-77. doi: 10.1007/s11307-0171082-x

89. D'Huyvetter M, De Vos J, Xavier C, Pruszynski M, Sterckx YGJ, Massa S, et al. I-131-Labeled Anti-HER2 Camelid sdAb as a Theranostic Tool in Cancer Treatment. Clin Cancer Res (2017) 23:6616-28. doi: 10.1158/1078 0432.Ccr-17-0310

90. Puttemans J, Dekempeneer Y, Eersels JL, Hanssens H, Debie P, Keyaerts M, et al. Preclinical Targeted Alpha- and Beta(-)-Radionuclide Therapy in HER2-Positive Brain Metastasis Using Camelid Single-Domain Antibodies. Cancers (2020) 12:1017-37. doi: 10.3390/cancers12041017

91. Cao L, Li Q, Tong Z, Xing Y, Xu K, Wang JY, et al. HER2-Specific Immunotoxins Constructed Based on Single-Domain Antibodies and the 
Improved Toxin PE24X7. Int J Pharm (2020) 574:1-41. doi: 10.1016/ j.ijpharm.2019.118939

92. Stoessel A, Groysbeck N, Guyot L, Barret L, Nomine Y, Nguekeu-Zebaze L, et al. Modular Conjugation of a Potent Anti-HER2 Immunotoxin Using Coassociating Peptides. Bioconjugate Chem (2020) 31:2421-30. doi: 10.1021/ acs.bioconjchem.0c00482

93. Zou T, Dembele F, Beugnet A, Sengmanivong L, Trepout S, Marco S, et al. Nanobody-Functionalized PEG-B-PCL Polymersomes and Their Targeting Study. J Biotechnol (2015) 214:147-55. doi: 10.1016/ j.jbiotec.2015.09.034

94. D'Hollander A, Jans H, Velde GV, Verstraete C, Massa S, Devoogdt N, et al. Limiting the Protein Corona: A Successful Strategy for In Vivo Active Targeting of Anti-HER2 Nanobody-Functionalized Nanostars. Biomaterials (2017) 123:15-23. doi: 10.1016/j.biomaterials.2017.01.007

95. Khaleghi S, Rahbarizadeh F, Ahmadvand D, Malek M, Hosseini HRM. The Effect of Superparamagnetic Iron Oxide Nanoparticles Surface Engineering on Relaxivity of Magnetoliposome. Contrast Media Mol Imaging (2016) 11:340-9. doi: 10.1002/cmmi.1697

96. Patris S, De Pauw P, Vandeput M, Huet J, Van Antwerpen P, Muyldermans S, et al. Nanoimmunoassay Onto a Screen Printed Electrode for HER2 Breast Cancer Biomarker Determination. Talanta (2014) 130:164-70. doi: 10.1016/ j.talanta.2014.06.069

97. Ambrosetti E, Paoletti P, Bosco A, Parisse P, Scaini D, Tagliabue E, et al. Quantification of Circulating Cancer Biomarkers via Sensitive Topographic Measurements on Single Binder Nanoarrays. ACS Omega (2017) 2:2618-29. doi: 10.1021/acsomega.7b00284

98. Ambrosetti E, Bernardinelli G, Hoffecker I, Hartmanis L, Kiriako G, de Marco A, et al. A DNA-Nanoassembly-Based Approach to Map Membrane Protein Nanoenvironments. Nat Nanotechnol (2021) 16:1-26. doi: 10.1038/ s41565-020-00785-0

99. Kijanka M, van Donselaar EG, Mueller WH, Dorresteijn B, Popov-Celeketic D, el Khattabi M, et al. A Novel Immuno-Gold Labeling Protocol for Nanobody-Based Detection of HER2 in Breast Cancer Cells Using Immuno-Electron Microscopy. J Struct Biol (2017) 199:1-11. doi: 10.1016/ j.jsb.2017.05.008

100. Debie P, Van Quathem J, Hansen I, Bala G, Massa S, Devoogdt N, et al. Effect of Dye and Conjugation Chemistry on the Biodistribution Profile of NearInfrared-Labeled Nanobodies as Tracers for Image-Guided Surgery. Mol Pharm (2017) 14:1145-53. doi: 10.1021/acs.molpharmaceut.6b01053

101. Ramos-Gomes F, Bode J, Sukhanova A, Bozrova SV, Saccomano M, Mitkovski M, et al. Single- and Two-Photon Imaging of Human Micrometastases and Disseminated Tumour Cells With Conjugates of Nanobodies and Quantum Dots. Sci Rep (2018) 8:10-22. doi: 10.1038/ s41598-018-22973-8

102. Soler MA, Medagli B, Semrau MS, Storici P, Bajc G, de Marco A, et al. A Consensus Protocol for the In Silico Optimisation of Antibody Fragments. Chem Commun (2019) 55:14043-6. doi: 10.1039/c9cc06182g

103. Lin L, Li L, Zhou C, Li J, Liu J, Shu R, et al. A HER2 Bispecific Antibody can be Efficiently Expressed in Escherichia Coli With Potent Cytotoxicity. Oncol Lett (2018) 16:1259-66. doi: 10.3892/ol.2018.8698

104. Wang Y, Wang Y, Chen G, Li Y, Xu W, Gong S. Quantum-Dot-Based Theranostic Micelles Conjugated With an Anti-EGFR Nanobody for TripleNegative Breast Cancer Therapy. ACS Appl Mater Inter (2017) 9:30297-305. doi: 10.1021/acsami.7b05654

105. Singh S, Murillo G, Chen D, Parihar AS, Mehta RG. Suppression of Breast Cancer Cell Proliferation by Selective Single-Domain Antibody for Intracellular Stat3. Breast Cancer-Basic Clin Res (2018) 12:7. doi: 10.1177/ 1178223417750858

106. Wang D, Hu X, Liu C, Jia Y, Bai Y, Cai C, et al. Protein C Receptor is a Therapeutic Stem Cell Target in a Distinct Group of Breast Cancers. Cell Res (2019) 29:832-45. doi: 10.1038/s41422-019-0225-9

107. Ji X, Han T, Kang N, Huang S, Liu Y. Preparation of RGD4C Fused AntiTNF Alpha Nanobody and Inhibitory Activity on Triple-Negative Breast Cancer In Vivo. Life Sci (2020) 260:1-10. doi: 10.1016/j.lfs.2020.118274

108. Liu Y, Ji X, Kang N, Zhou J, Liang X, Li J, et al. Tumor Necrosis Factor Alpha Inhibition Overcomes Immunosuppressive M2b Macrophage-Induced Bevacizumab Resistance in Triple-Negative Breast Cancer. Cell Death Dis (2020) 11:1-13. doi: 10.1038/s41419-020-03161-x
109. Funston G, Hardy V, Abel G, Crosbie EJ, Emery J, Hamilton W, et al. Identifying Ovarian Cancer in Symptomatic Women: A Systematic Review of Clinical Tools. Cancers (2020) 12:1-21. doi: 10.3390/cancers12123686

110. Chen K, Xue J, Zhou Q, Zhang Y, Zhang M, Zhang Y, et al. Coupling MetalOrganic Framework Nanosphere and Nanobody for Boosted Photoelectrochemical Immunoassay of Human Epididymis Protein 4. Analytica Chimica Acta (2020) 1107:145-54. doi: 10.1016/j.aca.2020.02.011

111. Ratan C, Cicily KDD, Nair B, Nath LR. MUC Glycoproteins: Potential Biomarkers and Molecular Targets for Cancer Therapy. Curr Cancer Drug Targets (2021) 21:132-52. doi: 10.2174/1568009620666201116113334

112. Peng L, Oberst MD, Huang J, Brohawn P, Morehouse C, Lekstrom K, et al. The CEA/CD3-Bispecific Antibody MEDI-565 (MT111) Binds a Nonlinear Epitope in the Full-Length But Not a Short Splice Variant of CEA. PloS One (2012) 7:3-17. doi: 10.1371/journal.pone.0036412

113. Hafian H, Sukhanova A, Turini M, Chames P, Baty D, Pluot M, et al. Multiphoton Imaging of Tumor Biomarkers With Conjugates of SingleDomain Antibodies and Quantum Dots. Nanomed Nanotechnol Biol Med (2014) 10:1701-9. doi: 10.1016/j.nano.2014.05.014

114. Zian Z, Berry SPD-G, Bahmaie N, Ghotbi D, Kashif A, Madkaikar M, et al. The Clinical Efficacy of Rituximab Administration in Autoimmunity Disorders, Primary Immunodeficiency Diseases and Malignancies. Int Immunopharmacol (2021) 95:107565-. doi: 10.1016/j.intimp.2021.107565

115. Vandenbroucke K, de Haard H, Beirnaert E, Dreier T, Lauwereys M, Huyck L, et al. Orally Administered L. Lactis Secreting an Anti-TNF Nanobody Demonstrate Efficacy in Chronic Colitis. Mucosal Immunol (2010) 3:49-56. doi: $10.1038 / \mathrm{mi} .2009 .116$

116. Kratz F, Elsadek B. Clinical Impact of Serum Proteins on Drug Delivery. J Control Release (2012) 161:429-45. doi: 10.1016/j.jconrel.2011.11.028

117. Steeland S, Puimege L, Vandenbroucke RE, Van Hauwermeiren F, Haustraete J, Devoogdt N, et al. Generation and Characterization of Small Single Domain Antibodies Inhibiting Human Tumor Necrosis Factor Receptor 1. J Biol Chem (2015) 290:4022-37. doi: 10.1074/jbc.M114.617787

118. Desmyter A, Spinelli S, Boutton C, Saunders M, Blachetot C, de Haard H, et al. Neutralization of Human Interleukin 23 by Multivalent Nanobodies Explained by the Structure of Cytokine-Nanobody Complex. Front Immunol (2017) 8:884. doi: 10.3389/fimmu.2017.00884

119. Beirnaert E, Desmyter A, Spinelli S, Lauwereys M, Aarden L, Dreier T, et al. Bivalent Llama Single-Domain Antibody Fragments Against Tumor Necrosis Factor Have Picomolar Potencies Due to Intramolecular Interactions. Front Immunol (2017) 8:867. doi: 10.3389/fimmu.2017.00867

120. Svecova D, Lubell MW, Casset-Semanaz F, Mackenzie H, Grenningloh R. Krueger JG. A Randomized, Double-Blind, Placebo-Controlled Phase 1 Study of Multiple Ascending Doses of Subcutaneous M1095, an AntiInterleukin 17A/F Nanobody, in Moderate-to-Severe. J Am Acad Dermatol (2019) 81:196-203. doi: 10.1016/j.jaad.2019.03.056

121. Gibson DJ, Ward MG, Rentsch C, Friedman AB, Taylor KM, Sparrow MP, et al. Review Article: Determination of the Therapeutic Range for Therapeutic Drug Monitoring of Adalimumab and Infliximab in Patients With Inflammatory Bowel Disease. Aliment Pharmacol Ther (2020) 51:61228. doi: 10.1111/apt.15643

122. Hanauer SB, Feagan BG, Lichtenstein GR, Mayer LF, Schreiber S, Colombel JF, et al. Maintenance Infliximab for Crohn's Disease: The ACCENT I Randomised Trial. Lancet (2002) 359:1541-9. doi: 10.1016/s0140-6736(02) 08512-4

123. Zheng Y, Danilenko DM, Valdez P, Kasman I, Eastham-Anderson J, Wu J, et al. Interleukin-22, a T(H)17 Cytokine, Mediates IL-23-Induced Dermal Inflammation and Acanthosis. Nature (2007) 445:648-51. doi: 10.1038/ nature 05505

124. Coppieters K, Dreier T, Silence K, de Haard H, Lauwereys M, Casteels P, et al. Formatted Anti-Tumor Necrosis Factor Alpha VHH Proteins Derived From Camelids Show Superior Potency and Targeting to Inflamed Joints in a Murine Model of Collagen-Induced Arthritis. Arthritis Rheum (2006) 54:1856-66. doi: 10.1002/art.21827

125. Van Roy M, Ververken C, Beirnaert E, Hoefman S, Kolkman J, Vierboom M, et al. The Preclinical Pharmacology of the High Affinity Anti-IL-6r Nanobody (R) ALX-0061 Supports Its Clinical Development in Rheumatoid Arthritis. Arthritis Res Ther (2015) 17:1-16. doi: 10.1186/ s13075-015-0651-0 
126. Marston HD, Paules CI, Fauci AS. Monoclonal Antibodies for Emerging Infectious Diseases - Borrowing From History. N Engl J Med (2018) 378:1469-72. doi: 10.1056/NEJMp1802256

127. Levi-Schaffer F, de Marco A. COVID-19 and the Revival of Passive Immunization: Antibody Therapy for Inhibiting SARS-CoV-2 and Preventing Host Cell Infection: IUPHAR Review: 31 . Br J Pharmacol (2021) 178:3359-72. doi: 10.1111/bph.15359

128. Hultberg A, Temperton NJ, Rosseels V, Koenders M, Gonzalez-Pajuelo M, Schepens B, et al. Llama-Derived Single Domain Antibodies to Build Multivalent, Superpotent and Broadened Neutralizing Anti-Viral Molecules. PloS One (2011) 6:1-12. doi: 10.1371/journal.pone.0017665

129. Pant N, Marcotte H, Hermans P, Bezemer S, Frenken L, Johansen K, et al. Lactobacilli Producing Bispecific Llama-Derived Anti-Rotavirus Proteins In Vivo for Rotavirus-Induced Diarrhea. Future Microbiol (2011) 6:583-93. doi: $10.2217 / \mathrm{fmb} .11 .32$

130. Rossotti MA, Gonzalez-Techera A, Guarnaschelli J, Yim L, Camacho X, Fernandez M, et al. Increasing the Potency of Neutralizing Single-Domain Antibodies by Functionalization With a CD11b/CD18 Binding Domain. Mabs (2015) 7:820-8. doi: 10.1080/19420862.2015.1068491

131. Herrera C, Klokk TI, Cole R, Sandvig K, Mantis NJ. A Bispecific Antibody Promotes Aggregation of Ricin Toxin on Cell Surfaces and Alters Dynamics of Toxin Internalization and Trafficking. PloS One (2016) 11:e0156893. doi: 10.1371/journal.pone. 0156893

132. Moayeri M, Tremblay JM, Debatis M, Dmitriev IP, Kashentseva EA, Yeh AJ, et al. Adenoviral Expression of a Bispecific VHH-Based Neutralizing Agent That Targets Protective Antigen Provides Prophylactic Protection From Anthrax in Mice. Clin Vaccine Immunol (2016) 23:213-8. doi: 10.1128/ cvi.00611-15

133. Wang SX, Michiels J, Arien KK, New R, Vanham G, Roitt I. Inhibition of HIV Virus by Neutralizing Vhh Attached to Dual Functional Liposomes Encapsulating Dapivirine. Nanoscale Res Lett (2016) 11:1-10. doi: 10.1186/ s11671-016-1558-7

134. Bobkov V, Zarca AM, Van Hout A, Arimont M, Doijen J, Bialkowska M, et al. Nanobody-Fc Constructs Targeting Chemokine Receptor CXCR4 Potently Inhibit Signaling and CXCR4-Mediated HIV-Entry and Induce Antibody Effector Functions. Biochem Pharmacol (2018) 158:413-24. doi: $10.1016 /$ j.bcp.2018.10.014

135. Steeland S, Van Ryckeghem S, Vandewalle J, Ballegeer M, Van Wonterghem E, Eggermont M, et al. Simultaneous Inhibition of Tumor Necrosis Factor Receptor 1 and Matrix Metalloproteinase 8 Completely Protects Against Acute Inflammation and Sepsis. Crit Care Med (2018) 46:E67-75. doi: $10.1097 / \mathrm{ccm} .0000000000002813$

136. Mars A, Bouhaouala-Zahar B, Raouafi N. Ultrasensitive Sensing of Androctonus Australis Hector Scorpion Venom Toxins in Biological Fluids Using an Electrochemical Graphene Quantum Dots/Nanobody-Based Platform. Talanta (2018) 190:182-7. doi: 10.1016/j.talanta.2018.07.087

137. Hussack G, Ryan S, van Faassen H, Rossotti M, MacKenzie CR, Tanha J. Neutralization of Clostridium Difficile Toxin B With VHH-Fc Fusions Targeting the Delivery and CROPs Domains. PloS One (2018) 13: e0208978. doi: 10.1371/journal.pone.0298978

138. Bernedo-Navarro RA, Romao E, Yano T, Pinto J, De Greve H, Sterckx YGJ, et al. Structural Basis for the Specific Neutralization of Stx2a With a Camelid Single Domain Antibody Fragment. Toxins (2018) 10:1-20. doi: 10.3390/ toxins 10030108

139. Strokappe NM, Hock M, Rutten L, McCoy LE, Back JW, Caillat C, et al. Super Potent Bispecific Llama VHH Antibodies Neutralize HIV via a Combination of Gp41 and Gp120 Epitopes. Antibodies (2019) 8:5-24. doi: 10.3390/antib8020038

140. Morales-Yanez FJ, Sariego I, Vincke C, Hassanzadeh-Ghassabeh G, Polman K, Muyldermans S. An Innovative Approach in the Detection of Toxocara Canis Excretory/Secretory Antigens Using Specific Nanobodies. Int J Parasit (2019) 49:635-45. doi: 10.1016/j.ijpara.2019.03.004

141. Huang P-N, Wang H-C, Hung H-C, Tseng S-N, Chang T-Y, Chou M-Y, et al. Antiviral Activity of a Llama-Derived Single-Domain Antibody Against Enterovirus A71. Antimicrob Agents Chemother (2020) 64:1-53. doi: $10.1128 /$ aac.01922-19

142. Huo J, Le Bas A, Ruza RR, Duyvesteyn HME, Mikolajek H, Malinauskas T, et al. Neutralizing Nanobodies Bind SARS-CoV-2 Spike RBD and Block
Interaction With ACE2. Nat Struct Mol Biol (2020) 27:846-+. doi: 10.1038/ s41594-020-0469-6

143. Lu Q, Zhang Z, Li H, Zhong K, Zhao Q, Wang Z, et al. Development of Multivalent Nanobodies Blocking SARS-CoV-2 Infection by Targeting RBD of Spike Protein. J Nanobiotechnol (2021) 19:33-45. doi: 10.1186/s12951021-00768-w

144. Xiang Y, Nambulli S, Xiao Z, Liu H, Sang Z, Duprex WP, et al. Versatile, Multivalent Nanobody Cocktails Efficiently Neutralize SARS-CoV-2. Science (2020) 8:1-34. doi: 10.1101/2020.08.24.264333

145. Dong J, Huang B, Wang B, Titong A, Kankanamalage SG, Jia Z, et al. Development of Humanized Tri-Specific Nanobodies With Potent Neutralization for SARS-CoV-2 (Vol 10, 17806, 2020). Sci Rep (2021) 11:4371-83. doi: 10.1038/s41598-021-82913-x

146. Sheikhi A, Hojjat-Farsangi M. An Immunotherapeutic Method for COVID19 Patients: A Soluble ACE2-Anti-CD16 VHH to Block SARS-CoV-2 Spike Protein. Hum Vaccines Immunother (2021) 17:92-7. doi: 10.1080/ 21645515.2020.1787066

147. Wu XL, Cheng L, Fu M, Huang BL, Zhu LJ, Xu SJ, et al. A Potent Bispecific Nanobody Protects Hace2 Mice Against SARS-CoV-2 Infection via Intranasal Administration. Cell Rep (2021) 37:109869-89. doi: 10.1016/ j.celrep.2021.109869

148. Schreur PJW, van de Water S, Harmsen M, Bermudez-Mendez E, Drabek D, Grosveld F, et al. Multimeric Single-Domain Antibody Complexes Protect Against Bunyavirus Infections. eLife (2020) 9:1-25. doi: 10.7554/eLife.52716

149. Ma H, Zeng W, Meng X, Huang X, Yang Y, Zhao D, et al. Potent Neutralization of SARS-CoV-2 by Hetero-Bivalent Alpaca Nanobodies Targeting the Spike Receptor-Binding Domain. J Virol (2021) 95:e0243820. doi: 10.1128/jvi.02438-20. JVI.02438-20.

150. De Tavernier E, Detalle L, Morizzo E, Roobrouck A, De Taeye S, Rieger M, et al. High Throughput Combinatorial Formatting of PcrV Nanobodies for Efficient Potency Improvement. J Biol Chem (2016) 291:15243-55. doi: $10.1074 /$ jbc.M115.684241

151. Herfst S, Schrauwen EJA, Linster M, Chutinimitkul S, de Wit E, Munster VJ, et al. Airborne Transmission of Influenza A/H5N1 Virus Between Ferrets. Science (2012) 336:1534-41. doi: 10.1126/science.1213362

152. Matrosovich MN, Matrosovich TY, Gray T, Roberts NA, Klenk HD. Neuraminidase Is Important for the Initiation of Influenza Virus Infection in Human Airway Epithelium. J Virol (2004) 78:12665-7. doi: 10.1128/ jvi.78.22.12665-12667.2004

153. Cardoso FM, Ibanez LI, Van den Hoecke S, De Baets S, Smet A, Roose K, et al. Single-Domain Antibodies Targeting Neuraminidase Protect Against an H5N1 Influenza Virus Challenge. J Virol (2014) 88:8278-96. doi: 10.1128/ jvi.03178-13

154. Mora AL, Detalle L, Gallup JM, Van Geelen A, Stohr T, Duprez L, et al. Delivery of ALX-0171 by Inhalation Greatly Reduces Respiratory Syncytial Virus Disease in Newborn Lambs. Mabs (2018) 10:778-95. doi: 10.1080/ 19420862.2018.1470727

155. Palomo C, Mas V, Detalle L, Depla E, Cano O, Vazquez M, et al. Trivalency of a Nanobody Specific for the Human Respiratory Syncytial Virus Fusion Glycoprotein Drastically Enhances Virus Neutralization and Impacts Escape Mutant Selection. Antimicrob Agents Chemother (2016) 60:6498-509. doi: 10.1128/aac.00842-16

156. Cunningham S, Piedra PA, Martinon-Torres F, Szymanski H, Brackeva B, Dombrecht E, et al. Nebulised ALX-0171 for Respiratory Syncytial Virus Lower Respiratory Tract Infection in Hospitalised Children: A Double-Blind, Randomised, Placebo-Controlled, Phase 2b Trial. Lancet Resp Med (2021) 9:21-32. doi: 10.1016/s2213-2600(20)30320-9

157. Granelli-Piperno A, Pritsker A, Pack M, Shimeliovich I, Arrighi JF, Park CG, et al. Dendritic Cell-Specific Intercellular Adhesion Molecule 3-Grabbing Nonintegrin/CD209 Is Abundant on Macrophages in the Normal Human Lymph Node and Is Not Required for Dendritic Cell Stimulation of the Mixed Leukocyte Reaction. J Immunol (2005) 175:4265-73. doi: 10.4049/ jimmunol.175.7.4265

158. Wong HL, Chattopadhyay N, Wu XY, Bendayan R. Nanotechnology Applications for Improved Delivery of Antiretroviral Drugs to the Brain. Adv Drug Delivery Rev (2010) 62:503-17. doi: 10.1016/j.addr.2009.11.020

159. da Cunha J, Maselli LMF, Stern ACB, Spada C, Bydlowski SP. Impact of Antiretroviral Therapy on Lipid Metabolism of Human Immunodeficiency 
Virus-Infected Patients: Old and New Drugs. J Virol (2015) 4:56-77. doi: $10.5501 /$ wjv.v4.i2. 56

160. Rao KVSE, Chitturi RT, Kattappagari KK, Kantheti LPC, Poosarla C, Baddam VRR. Impact of Highly Active Antiretroviral Therapy on Oral Manifestations of Patients With Human Immunodeficiency Virus/Acquired Immuno Deficiency Syndrome in South India. Indian J Sex Transm Dis AIDS (2015) 36:35-9. doi: 10.4103/0253-7184.156703

161. Klein F, Gaebler C, Mouquet H, Sather DN, Lehmann C, Scheid JF, et al. Broad Neutralization by a Combination of Antibodies Recognizing the CD4 Binding Site and a New Conformational Epitope on the HIV-1 Envelope Protein. J Exp Med (2012) 209:1469-79. doi: 10.1084/jem.20120423

162. Koh WWL, Steffensen S, Gonzalez-Pajuelo M, Hoorelbeke B, Gorlani A, Szynol A, et al. Generation of a Family-Specific Phage Library of Llama Single Chain Antibody Fragments That Neutralize HIV-1. J Biol Chem (2010) 285:19116-24. doi: 10.1074/jbc.M110.116699

163. Matz J, Kessler P, Bouchet J, Combes O, Ramos OHP, Barin F, et al. Straightforward Selection of Broadly Neutralizing Single-Domain Antibodies Targeting the Conserved CD4 and Coreceptor Binding Sites of HIV-1 Gp120. J Virol (2013) 87:1137-49. doi: 10.1128/jvi.00461-12

164. Hulsik DL, Liu Y-Y, Strokappe NM, Battella S, El Khattabi M, McCoy LE, et al. A Gp41 MPER-Specific Llama VHH Requires a Hydrophobic CDR3 for Neutralization But Not for Antigen Recognition. PloS Pathog (2013) 9:1-17. doi: 10.1371/journal.ppat.1003202

165. Kalusche S, Vanshylla K, Kleipass F, Gruell H, Muller B, Zeng Z, et al. Lactobacilli Expressing Broadly Neutralizing Nanobodies Against HIV-1 as Potential Vectors for HIV-1 Prophylaxis? Vaccines (2020) 8:1-21. doi: $10.3390 /$ vaccines 8040758

166. Renn A, Fu Y, Hall MD, Simeonov A, Hu X. Fruitful Neutralizing Antibody Pipeline Brings Hope To Defeat SARS-Cov-2. Trends Pharmacol Sci (2020) 41:815-29. doi: 10.1016/j.tips.2020.07.004

167. Czajka TF, Vance DJ, Mantis NJ. Slaying SARS-CoV-2 One (Single-Domain) Antibody at a Time. Trends Microbiol (2021) 29:195-203. doi: 10.1016/ j.tim.2020.12.006

168. Ahmad J, Jiang J, Boyd LF, Natarajan K, Margulies DH, Margulies DH. Structures of Synthetic Nanobody-SARS-CoV-2 Receptor-Binding Domain Complexes Reveal Distinct Sites of Interaction. J Biol Chem (2021) 4:101202. doi: 10.1016/j.jbc.2021.101202

169. Yao H, Cai H, Li T, Zhou B, Qin W, Lavillette D, et al. A High-Affinity RBDTargeting Nanobody Improves Fusion Partner's Potency Against SARS-CoV-2. PloS Pathog (2021) 17:e1009328-e. doi: 10.1371/journal.ppat.1009328

170. Koenig P-A, Das H, Liu H, Kummerer BM, Gohr FN, Jenster L-M, et al. Structure-Guided Multivalent Nanobodies Block SARS-CoV-2 Infection and Suppress Mutational Escape. Science (2021) 371:681-2. doi: 10.1126/ science.abe6230

171. Sun D, Sang Z, Kim YJ, Xiang Y, Cohen T, Belford AK, et al. Potent Neutralizing Nanobodies Resist Convergent Circulating Variants of SARSCoV-2 by Targeting Novel and Conserved Epitopes. Nat Commun (2021) 3:4676-87. doi: 10.1101/2021.03.09.434592

172. Aktories K, Schwan C, Jank T. Clostridium Difficile Toxin Biology. Annu Rev Microbiol (2017) 71:281-307. doi: 10.1146/annurev-micro-090816-093458

173. Wang F, Li Z-F, Yang Y-Y, Wan D-B, Vasylieva N, Zhang Y-Q, et al. Chemiluminescent Enzyme Immunoassay and Bioluminescent Enzyme Immunoassay for Tenuazonic Acid Mycotoxin by Exploitation of Nanobody and Nanobody-Nanoluciferase Fusion. Anal Chem (2020) 92:11935-42. doi: 10.1021/acs.analchem.0c02338

174. Van Overbeke W, Verhelle A, Everaert I, Zwaenepoel O, Vandekerckhove J, Cuvelier C, et al. Chaperone Nanobodies Protect Gelsolin Against MT1MMP Degradation and Alleviate Amyloid Burden in the Gelsolin Amyloidosis Mouse Model. Mol Ther (2014) 22:1768-78. doi: 10.1038/ mt.2014.132

175. Verhelle A, Nair N, Everaert I, Van Overbeke W, Supply L, Zwaenepoel O, et al. AAV9 Delivered Bispecific Nanobody Attenuates Amyloid Burden in the Gelsolin Amyloidosis Mouse Model. Hum Mol Genet (2017) 26:1353-64. doi: $10.1093 / \mathrm{hmg} / \mathrm{ddx} 056$

176. Pan H, Su Y, Xie Y, Wang W, Qiu W, Chen W, et al. Everestmab, a Novel Long-Acting GLP-1/Anti GLP-1R Nanobody Fusion Protein, Exerts Potent Anti-Diabetic Effects. Artif Cell Nanomed Biotechnol (2020) 48:854-66. doi: $10.1080 / 21691401.2020 .1770268$
177. Li X, Wang M, Zhang X, Liu C, Xiang H, Huang M, et al. The Novel LlamaHuman Chimeric Antibody Has Potent Effect in Lowering LDL-C Levels in Hpcsk9 Transgenic Rats. Clin Transl Med (2020) 9:1-12. doi: 10.1186/ s40169-020-0265-2

178. Fuchs H, Chen L-Z, Low S, Yu H. Ocular and Systemic Pharmacokinetics of BI-X, a Nanobody Targeting VEGF and Ang-2, After Intravitreal Dosing in Cynomolgus Monkeys - Evidence for Half-Life Extension by Albumin. Exp Eye Res (2021) 205:108486-. doi: 10.1016/j.exer.2021.108486

179. Ghislain J, Poitout V. Targeting Lipid GPCRs to Treat Type 2 Diabetes Mellitus - Progress and Challenges. Nat Rev Endocrinol (2021) 17:162-75. doi: 10.1038/s41574-020-00459-w

180. Tsujinaka H, Fu J, Shen J, Yu Y, Hafiz Z, Kays J, et al. Sustained Treatment of Retinal Vascular Diseases With Self-Aggregating Sunitinib Microparticles. Nat Commun (2020) 11:1-13. doi: 10.1038/s41467-020-14340-x

181. Pain C, Dumont J, Dumoulin M. Came Lid Single-Domain Antibody Fragments: Uses and Prospects to Investigate Protein Misfolding and Aggregation, and to Treat Diseases Associated With These Phenomena. Biochimie (2015) 111:82-106. doi: 10.1016/j.biochi.2015.01.012

182. Limbocker R, Mannini B, Cataldi R, Chhangur S, Wright AK, Kreiser RP, et al. Rationally Designed Antibodies as Research Tools to Study the Structure-Toxicity Relationship of Amyloid-Beta Oligomers. Int J Mol Sci (2020) 21:1-18. doi: 10.3390/ijms21124542

183. Aprile FA, Sormanni P, Podpolny M, Chhangur S, Needham L-M, Ruggeri FS, et al. Rational Design of a Conformation-Specific Antibody for the Quantification of A Beta Oligomers. Proceedings of the National. Proc Natl Acad Sci USA (2020) 117:13509-18. doi: 10.1073/pnas.1919464117

184. Messer A, Buder DC. Optimizing Intracellular Antibodies (Intrabodies/ Nanobodies) to Treat Neurodegenerative Disorders. Neurobiol Dis (2020) 134:1-33. doi: 10.1016/j.nbd.2019.104619

185. Butler DC, Joshi SN, De Genst E, Baghel AS, Dobson CM, Messer A. Bifunctional Anti-Non-Amyloid Component Alpha-Synuclein Nanobodies Are Protective In Situ. PloS One (2016) 11:e0165964. doi: 10.1371/ journal.pone.0165964

186. Chatterjee D, Bhatt M, Butler D, De Genst E, Dobson CM, Messer A, et al. Proteasome-Targeted Nanobodies Alleviate Pathology and Functional Decline in an Alpha-Synuclein-Based Parkinson's Disease Model. NPJ Parkinsons Dis (2018) 4:1-10. doi: 10.1038/s41531-018-0062-4

187. Vandesquille M, Li T, Po C, Ganneau C, Lenormand P, Dudeffant C, et al. Chemically-Defined Camelid Antibody Bioconjugate for the Magnetic Resonance Imaging of Alzheimer's Disease. Mabs (2017) 9:1016-27. doi: 10.1080/19420862.2017.1342914

188. Pansieri J, Plissonneau M, Stransky-Heilkron N, Dumoulin M, Heinrich-Balard L, Rivory P, et al. Multimodal Imaging Gd-Nanoparticles Functionalized With Pittsburgh Compound B or a Nanobody for Amyloid Plaques Targeting. Nanomedicine (2017) 12:1675-87. doi: 10.2217/nnm-2017-0079

189. Gerdes C, Waal N, Offner T, Fornasiero EF, Wender N, Verbarg H, et al. A Nanobody-Based Fluorescent Reporter Reveals Human Alpha-Synuclein in the Cell Cytosol. Nat Commun (2020) 11:1-13. doi: 10.1038/s41467-020-16575-0

190. Zorgati H, Larsson M, Ren W, Sim AYL, Gettemans J, Grimes JM, et al. The Role of Gelsolin Domain 3 in Familial Amyloidosis (Finnish Type). Proc Natl Acad Sci USA (2019) 116:13958-63. doi: 10.1073/pnas.1902189116

191. Rinaldi M, Denayer T, Thiolloy S, Tosar LCP, Buyse M-A, De Decker P, et al. ALX-0962, an Anti-IgE Nanobody (R) With a Dual Mode of Action. Eur Resp J (2013) 42:1575

192. Nisonoff A, Wissler FC, Lipman LN. Properties of the Major Component of a Peptic Digest of Rabbit Antibody. Science (1960) 132:1770-1. doi: 10.1126/ science.132.3441.1770

193. Labrijn AF, Janmaat ML, Reichert JM, Parren PWHI. Bispecific Antibodies: A Mechanistic Review of the Pipeline. Nat Rev Drug Discovery (2019) 18:585-608. doi: 10.1038/s41573-019-0028-1

194. Mohan N, Luo X, Shen Y, Olson Z, Agrawal A, Endo Y, et al. A Novel Bispecific Antibody Targeting EGFR and VEGFR2 Is Effective Against Triple Negative Breast Cancer via Multiple Mechanisms of Action. Cancers (2021) 13:1-19. doi: 10.3390/cancers13051027

195. Yi M, Zhang J, Li A, Niu M, Yan Y, Jiao Y, et al. The Construction, Expression, and Enhanced Anti-Tumor Activity of YM101: A Bispecific Antibody Simultaneously Targeting TGF-Beta and PD-L1. J Hematol Oncol (2021) 14:1-22. doi: 10.1186/s13045-021-01045-x 
196. de Marco A. Nanomaterial Bio-Activation and Macromolecules Functionalization: The Search for Reliable Protocols. Protein Expr Purif (2018) 147:49-52. doi: 10.1016/j.pep.2018.02.010

197. Kijanka M, Dorresteijn B, Oliveira S. Henegouwen PMPvBE. NanobodyBased Cancer Therapy of Solid Tumors. Nanomedicine (2015) 10:161-74. doi: $10.2217 / \mathrm{nnm} .14 .178$

198. Harwood SL, Alvarez-Cienfuegos A, Nunez-Prado N, Compte M, Hernandez-Perez S, Merino N, et al. ATTACK, a Novel Bispecific T CellRecruiting Antibody With Trivalent EGFR Binding and Monovalent CD3 Binding for Cancer Immunotherapy. Oncoimmunology (2018) 7:1-49. doi: 10.1080/2162402x.2017.1377874

199. Mandrup OA, Ong SC, Lykkemark S, Dinesen A, Rudnik-Jansen I, DagnasHansen NF, et al. Programmable Half-Life and Anti-Tumour Effects of Bispecific T-Cell Engager-Albumin Fusions With Tuned FcRn Affinity. Commun Biol (2021) 4:310-. doi: 10.1038/s42003-021-01790-2

200. Ackaert C, Smiejkowska N, Xavier C, Sterckx YGJ, Denies S, Stijlemans B, et al. Immunogenicity Risk Profile of Nanobodies. Front Immunol (2021) 12:632687. doi: 10.3389/fimmu.2021.632687

201. Godar M, de Haard H, Blanchetot C, Rasser J. Therapeutic Bispecific Antibody Formats: A Patent Applications Review (1994-2017). Expert Opin Ther Patents (2018) 28:251-76. doi: 10.1080/13543776.2018.1428307

202. Isbilir A, Serfling R, Moeller J, Thomas R, De Faveri C, Zabel U, et al. Determination of G-Protein-Coupled Receptor Oligomerization by Molecular Brightness Analyses in Single Cells. Nat Protoc (2021) 16:1419+. doi: 10.1038/s41596-020-00458-1

203. Sulea T, Hussack G, Ryan S, Tanha J, Purisima EO. Application of Assisted Design of Antibody and Protein Therapeutics (ADAPT) Improves Efficacy of a Clostridium Difficile Toxin A Single-Domain Antibody. Sci Rep (2018) 8:111. doi: 10.1038/s41598-018-20599-4

204. Soler MA, Fortuna S, de Marco A, Laio A. Binding Affinity Prediction of Nanobody-Protein Complexes by Scoring of Molecular Dynamics Trajectories. Phys Chem Chem Phys (2018) 20:3438-44. doi: 10.1039/ c7cp08116b
205. Cheng X, Wang J, Kang G, Hu M, Yuan B, Zhang Y, et al. Homology Modeling-Based in Silico Affinity Maturation Improves the Affinity of a Nanobody. Int J Mol Sci (2019) 20:1-19. doi: 10.3390/ijms20174187

206. Hu M, Kang G, Cheng X, Wang J, Li R, Bai Z, et al. In Vitro Affinity Maturation to Improve the Efficacy of a Hypoxia-Inducible Factor 1 Alpha Single-Domain Intrabody. Biochem Biophys Res Commun (2020) 529:93642. doi: 10.1016/j.bbrc.2020.06.097

207. Mahajan SP, Meksiriporn B, Waraho-Zhmayev D, Weyant KB, Kocer I, Butler DC, et al. Computational Affinity Maturation of Camelid SingleDomain Intrabodies Against the Nonamyloid Component of AlphaSynuclein. Sci Rep (2018) 8:1-14. doi: 10.1038/s41598-018-35464-7

208. Lindstedt PR, Aprile FA, Sormanni P, Rakoto R, Dobson CM, Bernardes GJL, et al. Systematic Activity Maturation of a Single-Domain Antibody With Non-Canonical Amino Acids Through Chemical Mutagenesis. Cell Chem Biol (2021) 28:70-+. doi: 10.1016/j.chembiol.2020.11.002

Conflict of Interest: The authors declare that the research was conducted in the absence of any commercial or financial relationships that could be construed as a potential conflict of interest.

Publisher's Note: All claims expressed in this article are solely those of the authors and do not necessarily represent those of their affiliated organizations, or those of the publisher, the editors and the reviewers. Any product that may be evaluated in this article, or claim that may be made by its manufacturer, is not guaranteed or endorsed by the publisher.

Copyright (c) 2022 Wang, Kang, Yuan, Cao, Huang and de Marco. This is an openaccess article distributed under the terms of the Creative Commons Attribution License (CC BY). The use, distribution or reproduction in other forums is permitted, provided the original author(s) and the copyright owner(s) are credited and that the original publication in this journal is cited, in accordance with accepted academic practice. No use, distribution or reproduction is permitted which does not comply with these terms. 